\title{
ELECTRON MICROSCOPE STUDIES
}

\author{
Progress Report \\ DOE ER 60437- ?
}

for Peried 1 July 1964 to 1 June 1992

A. V. Crewe and 0. H. Kapp

The University of Chicago

The Enrico Fermi Institute and

The Department of Physics

July 1, 1992

Prepared of

Th. U.S. Dept of Thate

Agrement Numler DLFC02867R6047 
DOE/ER/60437--7

DE92 040288

\section{ELECTRON MICROSCOPE STUDIES \\ Progress Report \\ DOE ER 60437-57}

for Period 1 July 1964 to 1 June 1992

A. V. Crewe and O. H. Kapp

The University of Chicago

The Enrico Fermi Institute and

The Department of Physics

July 1,1992

Prepared for

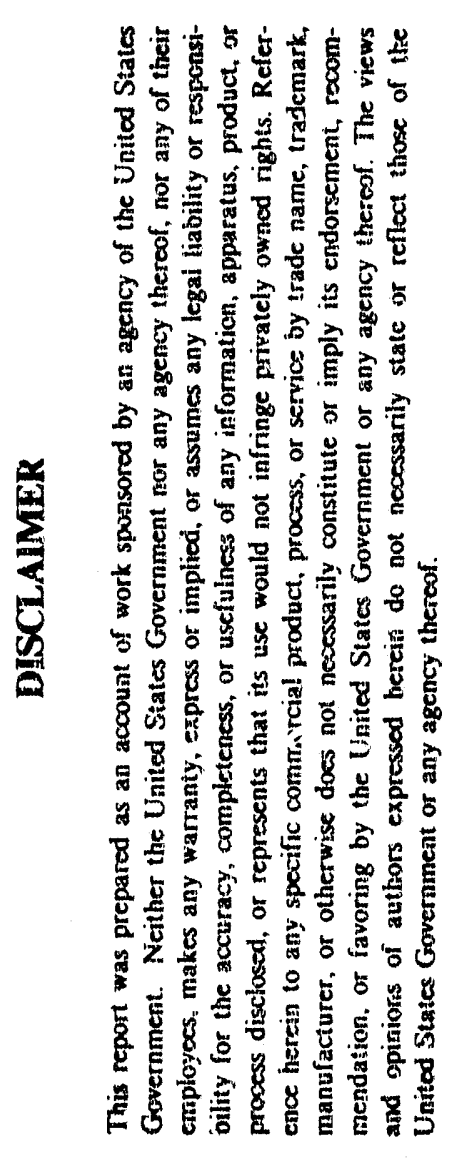

The U.S. Dept. of Energy Agreement Number DE-FG02-86ER60437 


\section{Notice}

This report was prepared as an account of work sponsored by the United States Government. Neither the United States nor the Department of Energy, nor any of their employees, nor any of their contractors, subcontractors, or their employees, makes any warranty, express or implied, or assumes any legal liability or responsibility for the accuracy, completeness, or usefulness of any information, apparatus, product or process disclosed or represents that its use would not infringe privately-owned rights. 


\section{Abstract}

This is a report covering the research performed in the Crewe laboratory between 1964 and 1992. Because of limitations of space we have provided relatively brief summaries of the major research directions of the facility during these years. A complete bibliography has been included and we have referenced groups of pertinent publications at the beginning of each section.

This report summarizes our efforts to develop better electron microscopes and chronicles many of the experimental programs, in materials science and biology, that acted both as a stimulus to better microscope design and also as a testing ground for many instrumental innovations. 


\section{Achievements of the Crewe Lab}

\section{Introduction}

In the following pages we will atternpt to chronicle the successes and the failures of the work of this laboratory from its inception in 1964 to the present. We will not try to cover all the administrative changes that have taken place, but merely note that the work began under the auspices of the AEC, continued through the era of ERDA and is now funded by the DOE. These changes were not functionally important because for most of these years, in fact until the past year, the personnel in the program management in Washington were the same.

It is impossible for us to tell the whole story in such a short space beause there is so much to tell. For example, our records indicate about 500 publications of various kinds, all the way from abstracts of presentations at the annual meetings of the microscope society to full length papers to chapters of books. Our records do not indicate how many invited talks have been given, but that must number in the hundreds. As one example, for the purposes of writing this report, we counted the number of references to our work in the Citation Index in the past 12 years. We counted more than 1000 such references and this was only to full length papers with rny name as the first one on the paper. It does not count references to shorter publications or to papers with someone else's name in first place. From this we can surmise that the total number of references to our work must be several thousand. We must conclude that our work has been appreciated.

We should also say at the outset that the work in this laboratory has been done by a large number of people over a number of years. There have been about a dozen graduate students and about as many undergraduates, postgraduates and other visitors. We will try to acknowledge all of them, but undoubtedly we will miss some.

This research program began when the author was still the Directur of Argonne National Laboratory, in 1963. At that time, I conceived a new principle for the construction of an electron microscope. The general idea was to focus a beam of electrons into $:$ very small probe and then scan the probe across the specimen in a raster fashion. The electrons passing through the specimen would pass through an energy analyzer and selected electrons would be used to provide the contrast in the image. This concept was very new anci it had the desirable property of separating the resolution (the probe size) from the contrast mechanism. However, it was completely 
unconventional. This type of microscope is now known as the STEM (scanning transmission electron microscope).

At that time, we were unaware of the efforts in England to develop a scanning microscope that used a totally different contrast mechanism, the secondary electrons. This was a successful effort and that type of microscope came to be called the SEM (scanning electron microscope). Perhaps it was a good thing that we knew nothing of this work since we might well have been very discouraged by the resolution calculations made by this group. They had come to the conclusion that a resolution better than about $50 \hat{\AA}$ was not possible! In fact, we had dimly appreciated this problem, which is associated with the type of electron source that they were using and which was the only one known at the time. Independently, we had concluded that the source would be a problem and we had decided to use a field emission tip for our electron source, even though they did not really exist anywhere.

After checking with experts in the laboratory that the idea really was a new one, a prototype version of such an instrument was designed and construction began. The mechanical parts were made in the Argonne shops while the electronics group designed and built the electronics. This was no easy task since the original concept involved the use of technology that was either not available at all or was only just coming into the market place. To take just one example, as we have pointed out above, the electron source was conceived to be a field emission source. While the phenomenon of field emission was well known, nobody had ever made an electron source based on this principle. The effect was still being used primarily for research into the effect itself. In fact, the vacuum levels that were needed for field emission were so far removed from the levels that could be maintained in a practical instrument that the experts in the field stated that it simply could not be done. We decided to produce the best possible vacuum and hope for the best.

For the record, it is relevant here to present the objections and comments that were made about this proposal at the time. These adverse comments had no real effect since "peer review" had not then been conceived and I was the director of the laboratory and therefore had some freedom in the matter of decision making.

The first objection wss the one given above, namely that field emission could not be made to work as a practical source of electrons. Specifically, we were told that the effect could only be seen when the varuum level was in the $10^{-15}$ Torr. range, a vacuum level that required the whole instrument to be placed in liquid Helium, and that the best that could be done in a working instrument would be in the $10^{-10}$ Torr range, a difference of a factor of $10^{5}$ ! 
The second objection was that no specimen could possibly tolerate a vacuum of $10^{-10}$, and even if they did survive, they would not represent the real object, the structures would be completely destroyed.

The third objection was that we could never maintain even the vacuum level of $10^{-10}$ in a working instrument because we would have persistent vacuum leaks and in any case, the only vacuum equipment on the market were the pumps and a few types of feedthroughs, notably linear motions. No rotary motions or electrical feedthroughs could be bought.

The fourth objection concerned the electronics. How could we possibly make the electronics stable enough to focus electrons into a spot a few $\AA$ in diameter?

The fifth objection was in the matter of a suitable image display system. The only image displays at the time were TV, which was then notably inferior, and oscilloscopes, which once again were so far short of the image quality available on the glass plates and film used in conventional electron microscopy as to be laughable.

These comments were made by the experts in the various fields and were obtained by the simple expedient of talking to them and asking for advice. In fact the only encouragement that I ever received was from people who knew nothing about technology but simply wanted better microscopes and welcomed any attempt to provide them.

There is absolutely no doubt that a proposal to construct this microscope would never have passed a peer review. The objections were good ones and there were few if any replies that 1 could give. Nevertheless, we proceeded with the project in the belief that all these problems could be solved. Nowadays, this type of proposal does not stand a chance. The peer review system, while having its merits, effectively prevents an innovator from even trying to do what he believes to be possible. The system does not allow for the situation where there are no peers. This comment is not meant to be arrogant, nor is it to be taken in the intellectual sense of the word, but simply to say that it is quite impossible for an innovator to set down on paper all the relevant thoughts that pass through his mind. Any rational discussion of these thoughts would occupy many days of talk and may not even lead to a definite conclusion. Peer review by mail does not allow the opportunity for discussion and without this discussion it can easily turn into a vehicle for anonymous and even defamatory carping.

We are reminded here of the recent explanations of the award of the Nobel prize in economics to Prof. Coase here at the University of Chicago. Many years ago he presented his views to the faculty. At the start of the discussions the vote was 20 to 1 against him. Stigler has pointed out that the vote would have been even worse if 
Coase had not been allowed to vote! At the end of a very long discussion, the vote was 21 to 0 in favor of his views. One wonders what might have happened if he had been forced to pass a peer review by mail in order to be able to proceed with his woik. It would never have been done.

\section{Construction (Reference Group A)}

When we began the design and construction of the instrument, nobody at Argonne (or indeed almost anywhere else) had experience with ultra-high vacuum (UHV) engineering and we all had to learn. Although there were some commercially available vacuum seals, we were forced to design many custom versions. The vacuum vessel that was built at that time is still in use and has never suffered from vacuum leaks. It is now 27 years old and still viable. It may be of some interest that the person who did the welding of all the mechanical joints was Frank Meyer. A few years later he put his experience to good use and founded Meyer Tool and Engineering Co. here in Illinois. This company specializes in high vacuum and cryogenic fabrication and is known throughout the USA. He does a great deal of work for Argonne and Fermilab.

At the very least this project gave the design and fabrication groups at Argonne some much needed experience and led to the formation of an industrial company of some size and competence.

\section{Source Development (Reference Group B)}

At Argonne I was joined by the first three graduate students who worked in my laboratory, Wall, Isaacson and Johnson. Together, we decided to find out how to build and operate a field emission source. For this purpose we designed and built a special unit for the rapid testing of the sources and in the course of about two years we begari to understand the process and how to obtain good performance. That work has continued to this day, because we still do not know enough. Nevertheless, we learned enough in those two years that we could operate a field emission source for a sufficient length of time to have a practical mic:oscope.

What we learned was that while the total emission current was far less in our kind of vacuum than that in a more perfect one, we could nevertheless obtain enough current for our needs. This was totally unpredicted. As our work proceeded, we were able to operate our tips for a day, then a week, then a month and finally, for several years without having to change them. This meant that our sources were even more reliable than even the very best conventional source. This again, was totally unexpected and so out of the ordinary that very few people believed our results. 
It was during this period that we were successful in obtaining our first images in the microscope. These images were unremarkable as regards the resolution but they did demonstrate that unusual contrast could be obtained. In fact, we published some images taken at various energy loss intervals. These images were the first to indicate the analytical power of the instrument and in that respect, it was the ancestor of many modern instruments.

Shortly : fter this work I resigned as laboratory director in order to return to the University of Chicago and the instrument was taken to the University. At that time, the AEC ( as it was then) decided to continue support of the project and placed it in the biological science area. This was an arbitrary decision since the research was applicable to many areas of science but until recently this has not been a problem. This is a very important point in veiw of the recent difficulties that we have encountered. The attitude of the program managers was always that the work was of high quality and that it could be considered to be a success even if the work did not directly beneit the biological sciences. As a result of this, we have always felt free to pursue productive lines of thought even if the ultimate benefit was to the material sciences! anywhere else. It would be a great loss if ideas generated in one area could not be followed through simply because of the narrow interests of the immediate source of funding. We have never been prevented from following our own noses but it appears now that this concept is not universally appreciated.

\section{STEM Development and Atomic Images (Reference Group C)}

In the period after our return to the University, we made several improvements to the microscope, but found that we could not obtain a resolution better than about $10 \AA$ and we then began some investigations into the theory of probe formation, an effort that continues today. We soon found that we had set our apertures incorrectly and when the aperture was properly adjusted, the resolution immediately improved to $5 \AA$. However, this was not the end of the story. We had been joined by Elmar Zeitler who was on a one year leave of absence. He gave our group some seminars on electron scattering and it became evident to me from these talks that our electron collection system could be improved. This inspired the idea of the annular detector for the elastically scattered electrons, perhaps the most important of all the contrast mechanisms. After installing an annular detector, we found that our resolution was really $2.5 \AA$ all the time, but we had not been able to see it because the contrast was too low.

In turn, this led to other ideas, notably that the use of the annular detector together with the energy loss spectrometer allowed us to provide almost complete separation between the elastic and the inelastic electrons. This meant that we were in a position to measure the mass of particles in the microscope and to measure the atomic number. 
Two pieces of information and two unknowns to solve for, the classical mathematical situation. Since that time, mass measurement and " $Z$ " contrast have become very important, the one in biology and the other more recently in materials science.

As we began to take images of smaller and smaller particles, we found that we could even obtain excellent images of unstained single stranded DNA. something that could not be dciie in a conventional microscope. This lead me to do the first calculations on the possibility of obtaining images of isolated atoms. The calculati is indicated that this was easily done for the casc of heavy atoms. Accordingly we looked around for a suitable sample and we were fortunate to heve the cooperation of Michael Beer from Johns Hopkins. He brought along a sample of a thorium compound that he had been experimenting with for the purpose of staining amino acids in DNA. All attempts to image the atoms in this or any other specimen had fauled. We were able to obtain clear images on the very first attempt.

Later, we continued to pursue this capability, pushing it as far as it would go. We imaged lighter and lighter atoms, finding a practical limit at about Zinc. We also tried to answer our critics (and there were many) by taking several successive images of the same atoms. To this date, I do not believe that anyone can do this using a conventional microscope. The act of viewing destroys that area of the specimen. But we could indeed do it because we had carefully investigated the contaniniation problem and learned how to control it. These lessons are still not heeded by most microscope operators. The final demonstration of our capabilities vas the production of movies showing the motion of atoms on the surface of the specimen, movies which involved taking hundreds of successive images of the same atoms. These movies were taken in 1974, long before anyone eise could obtain even one image of an atom.

Perhaps it is worthwhile to point out that very few people have been able to match this performance. The instrument that was put on the market by Vacuum Generators did not have a high enough resolution to be able to image single atoms until the introduction of their new machine just two years ago. Hitachi built a STEM for their research laboratory about 1980 and produced atom images, but they never introduced it to the market. Apart from that, the only microscopes that are able to image single atoms are the ones at Brookhaven (one of them is from Johns Hopkins) whose desig is are heavily based on ours.

The concept of the original instrument (now called the STEM) was taken up by only one company, Vacuum Generators of England. They simply took our basic design. and turned it upside down for convenience. In all other respects, it was identical to ours. There is no doubt at all that they violated the patents that were taken out by the AEC. Although I pointed this out to the AEC, they did nothing about it and I 
was informed that no royalties were ever received. In light of the fact that they have sold instruments with a total value in the neighborhood of 50 million dollars, these royalties alone could easily have kept our laboratory operating.

\section{The Field Emission SEM (Reference Group D)}

Shortly before we all returned to the University we decided to adapt the field emission source to the SEM microscopes then being developed in Cambridge England. When we calculated the resolution that we might expect, we found that we did not need any magnetic lenses in order to be able to compete with the miscroscopes then being sold. We found that our electron gun could provide all the focussing power that we needed. Naturally, this approach would not have been adequate for a commercial instrument because it could not provide the flexibility of operation that would be needed for general use. Nevertheless, we felt that there was a place for such a simplified approach. At the University we succeeded in making this device work and we took many images with it. In fact we used no lenses at all except for the lens action of the gun itself and we were able to demonstrate a resolution equal to the very best that could be done anywhere.

This concept was taken up by one of the engineers that worked on the project at Argonne. He teamed up with Vincent Coa es and they formed their own company, Coates and Welter. They produced the very first commercial instruments that used field emission sources. Their microscope design was almost identical to the one tha we worked on together. This company was eventually sold to American Optical and then later the technology was sold back to Coates, who founded Nanometrics, a company that still makes field emission microscopes, primarily for the semiconductor industry.

One other company took up our ideas and developed instruments and that is Hitachi of Japa 1. They decided to take our advice that field emission sourcer were the only ones capable of allowing the production of high resolution SEM instruments. They invested an enormous amount of effort into this program, with spectacular results. Violating no patents, because they were only interested in the SEM which was not covered by those patents, they developed many high performace instruments over the years. We have been reliably informed that they have sold more than 1700 microscopes with a total value that must be close to 500 million dollars. In view of this success, all the major manufacturers are now selling field emission microscopes, and it may not be long before all microscopes are of this kind. It would be safe to say that this laboratory is the source of a billion dollar industry.

Energy Loss and Radiation Damage (Reference Group E) 
When we decided to build the instrument described above, the development of the SEM was not our main concern. We were really more interested in the interaction of the electron beam with the specimen in the microscope. It was well known, of course, that the electron beam produces damage in the specimen and there had been demonstrations of the loss of information in the diffraction patteren obtained from crystalline specimens. Unfortunately there was little if any numerical data, principally because the conventional TEM is not a quantitative device. Also, since we had installed a spectrometer on the STEM in the faith and belief that the information obtained from it would be useful for image contrast, we needed to know more about the processes involved.

For these various reasons, we had installed a spectrometer of our own design on the simple SEM and we began a series of experiments to study the phenomena of energy loss and specimen damage. The work was done by a succession of graduate students, among them were Isaacson, Johnson, Lin and Ramamurti.

Since one of our primary targets was DNA, the first specimens that were studied were the four bases and later we included some amino acids. In each case, we could measure the rate of destruction of the specimen in terms of mass loss, loss of the energy loss peaks and loss of diffraction information. Using all this knowledge, we could put together a more or less complete picture of the damage process. We could even connect these processes in a general way with the known radiation chemistry (the G- values).

It is interesting that this picture was complete enough that Unwin returned to Cambridge from a conference in Europe where I piesented these results and then used them to design his famous experiment (with Henderson) on the imaging of the purple membrane.

In fact our series of experiments were conclusive enough that the numbers that were produced are the ones still in use today. They provide the basis for taking the steps needed to avoid radiation damage.

\section{Secondary Electron Production (Reference Group F)}

One other significant experiment that was done with this setup was an investigation into the origin of secondary electrons. This work was done by Voreades and is not generally known in the community. He chose to publish his results in a rather obscure journal. Since the results were used for his thesis he was entirely in control of the publication of his data. In fact, the data was very important and eventually lead me to reconsider the resolution limits of the SEM and this investigation had far reaching effects. 
Acting on my suggestion, Voreades set up an arrangement for detecting the secondary electrons in time coincidence with the energy loss electrons. In this way he could show that all regions of the energy loss spectrum contributed to the secondary electron current and that the electrons came from a very thin region near the surface. In carbon, this corresponded to a layer only $20 \AA$ thick. For heavier materials, the layer was even thinzer. This result allowed us to generate a picture of the process whereby energy loss events produce secundary electrons that wander around in the body of the material and emerge from the surtace if they have enough energy to escape. This is a simnie model and it works.

\section{DNA Labelling (Reference Group G)}

The story of the DNA labelling experiments is an interesting one with both good news and bad. It has relevance for the work. now underway on the human genome project.

When we demonstrated that single atoms could be seen in the microscope, one of the students (Langmore) decided to try to use this capability for visually sequencing strands of DNA. In the final version, the idea was to replicate single strands of DNA using thiolated bases. If this could be done selectively, the bases could then be labelled with mercury since the sulphur atom was exposed and reactive. The microscope would then be used to determine the spacing of the labels. The whole process could then be repeated by using different thiolated bases so that in the end there would be a great deal of redundancy in the data and sequencing should be virtually unambiguous.

Langmore succeeded in doing all the wet chemistry and was able to demonstrate that the various steps were all feasible and the reactions were selective enough to ensure success. This feat alone deserves a meda!!

The difficulty came when the specimen was put into the microscope. What he observed was that the mercury atoms moved away from their original positions and the movement was large enough that the whole experiment was doomed. In fact it was Langmore who first noted the movernent of atoms on the surface of the carbon film, an observation that led us to investigate this whole phenomenon. That investigation took too long to be of any value in the sequencing attempt and Langmore eventually worked on a different specimen for his thesis.

That series of experiments on the motion of single atoms indicated that the atorns were moving due entirely due to their thermal energy, or rather the ratio of the thermal energy to the binding energy on the film. One can conclude from this that it may yet be possible to do the type of experiment that Langmore envisaged. What would be needed would be a system with a higher atom - carbon binding energy and to operate 
at low temperatures. Unfortunately, we have never had another student who wanted to try to develop this technology, but this does not invalidate the conclusion.

\section{Nucleosomes (Reference Group H)}

The specimen that Langmore chose for his thesis was the nucleosome. He obtained very good images of them and used the data that had been obtained on the energy loss problem in a very clever way. He allowed the specimen to become damaged by the radiation and used the fact that the DNA was less sensitive to radiation damage than the protein. In this way he could determine the location of the DNA and he proposed a structure for the nuclessome. It is noteworthy what happeised next. After graduation he went to the MRC in Cambridge, England where he wanted to continue the work on nucleosomes, but was not allowed to since that problem was reserved for some of the "greats". The structure of nucleosomes that was eventually published by the Cambridge group was virtually identical to Langmore's structure, but his work orily received a glancing reference!

\section{Attempts at Aberration Correction (Reference Group I)}

It is well known that the limiting factors in the resolution of the electron microscope are the effects of the lens aberrations. This was fully recognized in the early days and the whole problem of lens aberrations has received a lot of attention over the years. The major contribution to this problem was made by Scherzer in 1936 when he showed that the aberration coefficierits of the lenses are always of the same sign. The coefficient of spherical aberration is negative and that of chromatic aberration is positive. He was very careful to state the conditions under which this statement is true and the result is linown today as Scherzer's Theorem. It applies to static fields with cylindrical symmetry and when the fields are defined by Laplace.

This theorem implies that the aberration coefficients can never be zero, aithough this can only be inferred. Many peoplc have confirmed his results (including me) and it can be assumed that he was absolutely correct. In effect, we showed that the only fields that can give zero coefficients are quite impractical because they involve fields that go to infinity at some point.

It is natural then to try to design lenses with smaller aberrations. Many investigators have tried to do this over the past 50 years or so and it is reasonably safe to assume that everything that can be done in this direction has been done. In fact the situation is a very difficult one. The coefficent of chromatic aberration is closely equal to the focal length of the lens and the only possiblilty is to reduce that number. Even if the 
required field strengths could be obtained, there would be no room for the specimen. In addition, the resolution limit defined by the chromatic aberration depends on the square root of the coefficient. This means that if we want to make an improvement of a factor of two, we need to inprove the aberration coefficent by a factor of four.

The situation is even worse when the limit of resolution is determined by the spherical aberration. This coefficient is, 2 t best, about one half the focal length and the resolution depends on the fourth roo' of the coefficient so that an improvement by a factor of two means that the coefficient o" spherical aberration must be reduced by a factor of sixteen. It can be said quite positively that no such factor can be found by design improvements.

It was ciear to Scherzer that the limit of resolution could only be reduced by using field distributions that avoided one or more of the constraints that he had identified. In 1946 he deviseci a system of multipole lenses that together could act as a correction system for a normal lens. Over the course of the next few years he and his students investigated the optical requirements of this corrector and came to some alarming conclusions. In particular, they discovered that the alignment requirernents were very severe indeed. For example, all the 40 or so pole pieces needed to be placed in their proper positions within one tenth of a micron. This, of course, is mechanically impossible.

Some encouragement was obtained when Deltrap published his thesis for work: done in Cambridge. He constructed a model of the Scherzer corrector, scaling up the system to bench size in order to be able to test the functionality without, of course, being able to obtain high resolution. He simply wanted to show that the general principle would work. It did.

In due time, the Scherzer group devised ways to overcome all the problems, at least on paper. Construction began around 1970 but the system never worked. Shortly before he died. Scherzer wrote that the primary reason for the failure was the inadequate financial support for the project. I personally believe that he was quite correct in this conclusion. At that time, this was the most ambitious electron optical project ever conceived but the manpower that he had available was very limited.

Even while our group was still at Argonne, I began to think about the problem of aberration correction because it was certain that sooner or later we would run into the resolution problem. It seemed to me that the corrector design problem would be different for a STEM than for a conventional microscope and I asked David Cohen to look into the problem. He enlisted some outside help and eventually came up with a design that looked simpler than the Scherzer one. I redesigned the system to fit the parameters of our microscope and looked around for someone to build it. Here, we 
were fortunate that we had decided to return to the University of Chicago because there we found perhaps the only person in the country with the skills to fabricate the lenses to the tolerances that seemed necessary. That was Walter Mankowich. Over the course of the next few years he devised a method of making the pole pieces that seemed to be good enough. In fact, when the system was finally assembled, all 40 pole pieces were within 1 micron of their design positions, a truly remarkable feat. Naturally we knew that this would not be good enough for the system to work properly and we had incorporated trimming coils to provide the final adjustment. It turned out later that Scherzer had instituted essentially the same system of trimming coils.

In the meantime, we had built a special microscope for testing the corrector. This was a $100 \mathrm{kV}$ instrument that was put together by Vernon Beck, the graduate student who wanted to attempt the correction. Unfortunately, we could never make the corrector work. The reasons were varied, but the main reason was that the mechanical center of the multipole lenses was very different from the magnetic center and in addition, the magnetic center moved around with the excitation so that we could never align the system and maintain this alignment. After many hearibreaking attempts, we were forced to admit defeat.

Until 1980, the Scherzer corrector was the only known method for correcting aberrations in the electron microscope, and as we have just pointed out, it could not be made to work. However, in that year we invented a new method that looked very promising. In some purely theoretical studies on the electron optical properties of the various multipole elements, we discovered that the third order aberration of a sextupole lens is cylindrically symmetric and has the opposite sign of aberration from that of a round lens. Some time later, we devised a system of lenses that can use this effect to form a new type of corrector.

The publication of the sextupole corrector paper attracted a great deal of attention and in the interval since then a number of people have checked the calculations using a variety of different methods. There is universal agreement that the calculations are correct and that a corrector can be made.

We carefully investigated the construction problem and evaluated a few different options. One was to build a demonstration column that would simply confirm that the principle would work. Such a column would not have the high resolution possibilities of a full scale version. Another option was to build a system that would have the high resolutior. capabilities. To do this, however, meant that we would have to build an entirely new piece of equipment. The reason for this is that correcting the spherical aberration alone would not give a convincing improvement in the case of a microscope operating at the voltage that we normally use $(30 \mathrm{kV})$. Chromatic aberration becomes 
importint surprisingly soon. We looked at this problem very carefully and in doing so we were forced to reevaluate the limiting factors in the resolution capabilities of all probe forming microscopes. As we will show later, this work lead to some very significant improvements in other microscopes. In fact, the whole sextupole corrector project will have been worth the effort even if it never works!

In the end, we proposed the construction of a $200 \mathrm{KV}$ STEM with a sextupole correcting element. This proposal was made to the NSF and was eventually funded, but not at the requested level. The entire system of lenses and corrector has been designed and everything has been fabricated with the exception of a few portions of the electronics. Some of the components have also been tested. Unfortunately, the support has not been adequate for completion of the project and progress has therefore been very slow in recent years.

It should be noted that two of the visitors who worked in our laboratory, Er-gang Chen and $\mathrm{Mu}$, returned to China and began working on the problem of the sextupole corrector. They chose to build a simpler version that they could use for demonstration purposes. Within the past year or so they have produced real evidence that the corrector works. They have done this in the same way that Deltrap showed the original Scherzer corrector works. They will eventually try to obtain high resolution and we wish them well.

Until this past summer, the sextupole corrector was still the only corrector that shows promise of allowing the design and construction of an electron microscope of super high resolution in the normal voltage range for transmission microscopes. However, we have now invented a new method of aberration correction that seems to be much simpler.

One of the electron optical elements that Scherzer did not take into account and which is excluded by his theorem is the electron mirror. It has been known for decades that the mirror has the property that the sign of both aberration coefficients are opposite to those in the normal round lens. The difficulty has always been that the first order properties of the mirror are difficult to deal with and the mirror optics themselves have never been given much scrutiny. A discussion of the properties of the mirror can be found in old texts such as Zworykin, but one finds little encouragement there for the construction of a working system. Nevertheless, there have been several investigations in the past and recently the mirror was revived by Rempfer who proposed an idea for a corrector. It is reasonabiy certain that the Rempfer idea will not work, at least for high resolution systems, for a variety of reasons that are too complicated for discussion here. 
We began our own investigation into mirrors quite recently and during the past summer, we developed some new ideas on a particular form of mirror that seents to have all the desirable properties without any of the "side effects". We developed a complete proposal for a mirror corrector and have transmitted a proposal containing that idea to the NSF. This mirror corrector has the nice property that both spherical and chromatic aberration can be corrected.

It is interesting that we cannot yet confirm the details of operation of the corrector using numerical calculations because there do not appear to be any numerical methods for the solution of this type af problem. The difficulty is the reversal of the direction of motion. It may be that there are some techniques that can be used but we have not yet found them. However, there is no doubt that correction can occur because the physics of the problem is very simple and the effect can easily be demonstrated on paper.

At the moment we are developing an extension of the principle that might allow the design of a super high resolution SEM.

In summary, we can say that in 1946 Scherzer invented a corrector. He worked on the problem for more than 35 years and was unable to make it work. We tried to make the same kind of corrector work and we also failed. In 1980 we invented a second type of corrector. That corrector is still under construction here and the Chinese have also begun to develop the idea. Our work has been impeded by lack of funds. In 1991 we invented a third corrector and this one seems to be simpler than the others and more likely to work. We believe that this general concept will lead to yet another corrector, this time for the SEM. Such a development would have significant applications in biology and also in the semiconductor industry. Finally, as we will see later, this whole problem area led us to a reassessment of the resolution problem and to general improvements in the microscope business that are still having ramifications today.

\section{Theoretical Electron Optics (Reference Group J)}

Throughout this whole period we have been interested in the theoretical aspects of electron optics and although this is not our main activity, it has often been necessary to extend the field in order for us to proceed with the experimental work.

As one example, we have performed countless calculations of the properties of magnetic lenses. The vast majority of these calculations have never been published because it was feit that they had no general interest to the community. Nevertheless, these calculations have given us a unique insight into the properties of lenses and that in turn has enabled us to design lenses for particular purposes with far more confidence than we could have done otherwise. It may be noted that lens design is as much an 
art as it is a science. It is surely possible to calculate the focal properties of any lens that one cares to specify. The problem is how to specify the lens in the first place. Only by having the experience can one guess at the most appropriate design for a particular purpose. In other words, one gets to know where not to look.

Our interest in the problem of aberrations has also forced us in to theoretical electron optics. Not only were we motivated to develop the theory for our correctors, but it was also necessary to investigate very carefully the foundations of Scherzer's theorem. This lead to some interesting, if academic conclusions that had not been noticed previously. In fact we were able to give convincing proof that zero aberrations could only be obtained with magnetic fields that have pathological parameters and cannot be made in practice.

We have described some of our ether efforts in theory above, but we can add here a brief description of our latest efforts.

Over the course of twenty five years or so, we have developed a set of what we might call "rules of thumb" for the design of lenses and electron guns. These ruled seemed to work, but were not based on any known theory. $V_{\text {r }}$ set out to develop that theory about two years ago. In a series of three papers we took a close look at the focal properties of weak lenses, both electrostatic and magnetic. We developed a theory and performed some careful calculations to verify the results. The calculations were not easy to perform for the simple reason that we were looking at the extreme case of very weak lenses and this takes an inordinate amount of computer time. Fortunately, we have our own mainframe computer so that we could afford the time. The results were extremely interesting and have now been published. This ailows anyone to obtain approximate values for the focal length and the aberration coefficients of both types of lens. These approximations are good enough that they also work even for stronger lenses.

The most recent theoretical work was described above, namely the study of the motion of electrons in uniform fields. These calculations were described in the section on aberration correction.

It might be suspected that this type of field had been thoroughly investigated in the past since it is an obvious problem. Indeed, this is true except for the fact that these were very early investigations by the pioneers in the field and the algebra was done long ago, long before the question of aberrations had been raised and before they had been well defined. Since we could not find an adequate treatment of the problem in the literature, it seemed worthwhile to write down the equations and solve them. We looked at four separate configurations of magnetic and electrostatic fields and obtained the solutions to the equations of motion. The interesting thing was that we 
found that two of the configurations had aberrations of the opposite sign to the normal ones. This raised several issues and suggested several applications of the ideas.

- Two of the applications are in the area of high resolution microscopy and will be the subject of our renewal proposal. Other possibilities include improved massspectromenters and also improvements to ion microscopes.

\section{Optimization and the Super High Resolution SEM (Reference Group K)}

The work that we did on the optimization of the parameters of scanning microscopes bears some discussion here.

A few years ago it became apparent that the resolution of the SEM was stuck at about $15 \AA$. The microscopes from all the manufacturers had the same resolution and it appeared that nothing could be done about it. Many investigators were concerned with this issue and our involvement in it was motivated by a suggestion by a distinguished colleague that the only way to obtain better resolution would be to design and build a $200 \mathrm{kV}$ SEM. This was obviously bad physics because it completely ignored the non-local nature of the production of secondary electrons.

It should be noted that it may be unfair to criticize that colleague since we had considerably more experience with this problem. Not only had we done some research in the area of secondary electron production (see the discussion above), but we had some earlier experience with the theory of cloud chambers and bubble chambers and other detectors in high energy physics. The general concept of non-local inelastic scattering is common knowlege in those areas, but not in microscopy, although any graduate student in physics ought to have some familiarity with the concept.

In any case, it seemed important to perform an in-depth study of the physics of the resolution problem. We had already begun such a study for the STEM and it was a natural extension to consider the SEM.

With regard to the STEM, the factors to be studied included spherical aberration, chromatic aberration and diffraction. In our case, since we were considering the possibility of correcting the spherical aberration, the particular focus was on the effect of the fifth order aperture aberration. These calculations were done using wave-optical analysis and represented the best that could be done with the problem. We had hoped that this study would put to rest forever the gross approximation to the resolution problem that occurred often in the literature, namely taking the R.M.S. of all these effects, an operation that is akin to taking the average of an apple, an orange and a 
banana. Unfortunately, that statement still appears and we have given up correcting the authors.

In the case of the SEM which operates at lower voltages and where the contrast mechanism uses inelastic scattering, we must take into account the fact that these collisions can occur at large distances from the electrons. That is to say, the classical impact parameter can be several $\AA$. Fortunately, we were well aware of this problem in microscopy since it is this fact that limits the use of inelastic scattering for high resolution images in the STEM. We have often demonstrated this by taking simultaneous images of atoms using elastic and inelastic electrons. At $35 \mathrm{kV}$, the effect is very obvious and we had already published the data. It was then only necessary to extend the argument to the case of the SEM.

The conclusions of this study were that with proper optimization of the aperture in the SEM, ising wave optical calculations instead of gross averaging, the resolution shoulc inprove to about 5-7 $\AA$, and that the best operating voltage would be about 5 $\mathrm{kV}$.

The only manufacturer who listened to these arguments and did something about it was Hitachi, although all of them had access to the information. Hitachi designed a special instrument, the 900 series and it worked. Overnight, the best resolution of the SEM went from $15 \AA$ to $7 \AA$. It took several years before the other manufacturers caught up with Hitachi, but today virtually all of them offer such an instrument, with the exception of the one U.S. manufacturer (Amray).

We believe that this one contribution would justify the whole cost of our research support.

\section{Image Processing (Reference Group L)}

As a result of the measurements that we made on the radiation sensitivity of biological materials, we began to investigate the imaging properties of our microscope. The conventional electron microscope was very well suited for the study of molecules that could be crystallized into a regular array. This was the technique that was used by Unwin and Henderson in their study of the purple membrane. They were able to reconstruct the molecule from the information in the diffraction pattern, information that came from many different mulecules. By using many different molecules to provide an image of just one, they could minimize the effects of radiation damage. We could not do this with the same degree of efficiency and therefore we would tend to produce more damage in the specimen. 
The reverse side of the coin is that the conventional microscope is not very good for taking images of molecules that cannot be formed in to a regular array. Many molecules are such that they can only be imaged one at a time. On the other hand, the STEM can provide very good images of isolated molecules and the contrast is so good that excellent images can be obtained with far less dose than in the conventional TEM. We therefore began a program of imaging molecules and developing digital image processing techniques to take advantage of these capabilities.

The first work in this area was by Golladay, who studied negatively stained myosin. By careful digital analysis of the image, working line by line and doing very careful averaging, he was able to locate the uranyl atoms with considerable precision. In doing so he introduced us to the general idea of digital image processing. Partially because of this success, we began to develop a more complete processing system using a Nova computer with the vast (for then) memory of $32 \mathrm{k}$. In order to avoid the repititious work of programming, we developed an interactive image processing system where most of the operations could be done using a trackball and cursor. Later this capability was transferred to the IBM mainframe when we acquired one. We used the same philosophy and we have cuntinued to add to its capabilities. The net result is a very powerful image processing system that can be operated by inexperienced operators. Virtually everything can be done without the need to do any programming at all.

More recently, this program has been rewritten and transferred to a workstation environment since the capabilities of these devices are now at least as good as our original mainframe.

The use of this system will be described in subsequent sections.

\section{Three-Dimensional Reconstruction (Reference Group M)}

The hemoglobin program in this laboratory initially concentrated on the use of low-dose images because this opened up several new possibilities. Specifically, by adding many such images together we could produce one image with good signal to noise ratio without sustaining the commensurate amount of damage. In this way we could produce the same quality of image that can be obtained from a conventional microscope when the specimen can be formed into two dimensional ordered arrays. Unfortunately this cannot be done with hemoglobin but our low-dose method is potentially just as good and the STEM can operate with lower doses than a conventional microscope.

The images that were obtained by this method were very good indeed and furthermore, we were able to obtain images in three different projections, corresponding to three views taken 45 degrees apart. It was therefore natural to think of performing 
some kind of reconstruction in order to look at the molecule in 3D. Unfortunately, there was no existing algorithm to do this and there were many indications that it could not be done at all. All the algorithms for $3 \mathrm{D}$ reconstruction required many different views and indeed, required them to be taken at regular intervals. We simply could not do this, we had only three views but the images were of high quality.

In considering this problem it seemed possible that other investigators had ignored some factors and also that they were using other methods that had inherent inconsistencies.

First of all, the only method that we could find that seemed to apply to our specimen was a form of algebraic reconstruction. In this method the first step is to add the three projections together into a 3D array. This step appeared to be wrong and indeed we felt that it could conceivably introduce significant errors. The reason for the suspicion is that any reasonable operation on the data ought to at least retain zeros. That is to say, if there is no mass apparent at a particular location in the image then this is a valuable piece of information that must be maintained. The algebraic method does not do this. That first step can introduce mass into one of the projections from one of the others.

We preferred to think of the problem in terms of probabilities. If a certain mass density is seen at a particular location in one of the projections, that mass has an equal probability of being found at any of the locations along the line of sight. The characteristic of probabilities is that they must be multiplied together, not added. Therefore our fiist step consists of multiplying the three projections together in order to find the starting point for the reconstruction. This automatically retains all zeros.

The point that appeared to have been missed is that the hiological material that we are using in the microscope has a uniform density. If thers is any material at all at a particular point then it has everywhere the same density. There either is or is not some material at a lattice point. The problem is then a Boolean one. We are looking for ones and zeros, with nothing in between.

Given these two facts, our reconstruction problem reduces to utter simplicity. We multiply the probabilities in order to obtain a starting $3 \mathrm{D}$ matrix. We then take the maximum value and assume that there is indeed a one at that point. The value that existed at that point is then replaced with a one and the matrix is recalculated. Once again, the maximum value is replaced with a one and so on until the total mass discovered equals the total mass of the original object. 
Surprisingly, the method worked, alkhough the first run took a great deal of computer time. Subsequently the tuethos bis been refined in order to increase the speed. The reconstructions obtained by this method and the various refinements that have been added since are the best that have ever been obtained of ti: is molecule and the data matches that obtained subsequently elsewhere. All the evidence that we have indicates that this method does produce an accurate reconstruction.

\section{Hemoglobin Work (Reference Group N)}

We have had a program of study into the structure and function of the invertebrate hemoglobins that has extented over the past thirteen yeirs. The invertebrate hemoglobins represent a very broad range of respiratory proteins both in terms of structure and function. Their morphology can vary from single myoglobin-sized subunits to aggregates of several million molecular weight. In addition, their functional characteristics are complex and represent a variety of solutions to the need to deliver oxygen to tissue under profoundly different environmental conditions such as deep sea hydrothermal vents and oxygen-depleted polluted rivers. As a result of this complexity they represent attractive candidates for the study of structure-function relationships. Our primary approach has been to modify the protein using biochemical techniques, observe the attendant functional modifications and relate this to the observed structure in the STEM.

This work began when a graduate student of Serge Vinogradov (O. Kapp) traveled to our laboratory in the Fall of 1979 seeking STEM examination of his hemoglobin preparations. Kapp learned the use of the STEM from our then chief technician, Mitsuo Ohtsuki. Ultimately Kapp's thesis included a large amount of work done in this laboratory. Following his thesis defense (Spring, 1982) he jointed our group as a Research Associate. When Dr. Ohtsuki returned to Japan in 1985, Kapp took over the operation of the microscopes and presently holds positions at the Enrico Fermi Institute and also an Assistant Professorship in the Biological Sciences Division.

A particularly significant aspect of this work was the close working relationship of a biochemist with a top-notch electron microscope technician and physics-oriented graduate students. Generally, close proximity of the aforementioned groups is rare and the usual condition is one in which there are problems of communication due to everything from lack of physical proximity to differencess in culture and language that are a natural part of the indoctrination of each discipline.

Our research into $3 \mathrm{D}$ reconstruction techniques was stimulated by the desire of Kapp to obtain 3D structural data from STEM images of his preparations. Three of our Ph.D. students worked on this topic and a substantial number of publications resulted. In addition to obtaining $3 \mathrm{D}$ reconstuctions of several invertebrate hemoglobins, 
we were able to obtain reconstructions of depleted preparations in which one or more subunits were missing. With this team we were able to correlate the results of biochemical separation techniques such as colunin chromatograhy and SDS electrophoresis with data from the STEM and subsequently obtained differential reconstructions which mapped the location of the missing subunits by comparison with the $3 \mathrm{D}$ map of the native molecules.

One of the earliest observations we made by STEM of the invertebrate hemoglobins was the greater-than-expected dimensions obtained for intact, native dodecamers. The annelid extracellular hemoglobins are composed of a bilayer of hexameric structures forming a complex with a diameter of about $300 \AA$ and a height of about $200 \AA$. All previous reports of this group of proteins pointed towards dimensions of about. $250 \mathrm{x}$ $160 \AA$. Because the STEM has no post-specimen optics and images are taken in-focus our dimensions are likely to be more reliable because of the absence of phase contrast reversal effects at an unknown resolution limit. Our dimensions were corroborated by the dimensions obtained for wet crystals of Lumbricus hemoglobin by Prof. Warner Love. This along with other observations led us to believe that STEM of negativelystained specimens of these proteins provided useful and meaningful results.

One of the first experiments we performed in the STEM was the examination of the alkaline dissociation products obtained by exposure of Lumbricus hemoglobin to pH 9 for 24 hours followed by column chromatography to separate the various size classes. In addition, these fractions were combined and re-exposed to neutral $\mathrm{pH}$ to generate a re-associated molecule. This observation led to experiments in which we would remove various subunits and observe the subsequent effect on the reassociation process. Subtle changes in the morphology of the re-associated molecule could be observed using false-color display. For example, a 5\% difference in scattering crosssection of the $1 / 12$ th subunit, a difference not visible in grey-level display was easily discerned using a color palette of just 256 colors. We demonstrated that these subtle structural alterations were reproducible and were associated with dramatic changes in the functional characteristics of the molecule. For instance, the intact, native hemoglobin of Lumbricus displays a Hill coefficient $n$ of about 4.3 at neutral pH. The re-associated molecule, however, provided values of about 2.3 , the same value obtained for the putative $1 / 12$ th subunit.

We also observed the dissociation-reassociation process described above for hemoglobin preparations that had been exposed to acid $\mathrm{pH}$ and then returned to neutral $\mathrm{pH}$. The same functional alterations in the molecule were also observed.

This work then led to the examination of preparations in which one or more subunits were removed before reassociation. One of the most striking results obtained 
with the STEM was the observation of hexagonal bilayers in preparations of Lumbricus hemoglobin in which the smallest heme-containing subunit (by SDS-PAGE) was completely absent. The location of this subunit was approximated by subtracting the 3D reconstruction of the native hemoglobin from the $3 \mathrm{D}$ reconstruction of the depleted preparation. The central hole in the molecule was nearly identical in size in the two preparations and it was thus assumed that the depletion about the outer periphery of the reassociated molecule was due to the absence of this particular subunit.

Our research into $3 \mathrm{D}$ reconstruction techniques was stimulated by a desire to obtain 3D structural data from STEM images of various biological specimens. Three of our Ph.D. students worked on this topic and a substantial number of publications resulted. In addition to obtaining $3 \mathrm{D}$ reconstuctions of several invertebrate hemoglobins, we were able to obtain reconstructions of depleted preparations (described above) in which one or more subunits were missing. With this team we were able to correlate the results of biochemical separation techniques such as column chromatograhy and SDS electrophoresis with data from the STEM and other techniques such as neutron scattering and low-angle $\mathrm{x}$-ray scattering.

One of the problems encountered in the reconstruction of non-periodic objects is the determination of the relative orientation in which the biological macromolecule appears on the substrate. We looked at this problem using multivariate statistical techniques and developed algorithms for classification of molecules into sub-groups according to orientation. This work began with classification of orientation about a single rotation axis and then was extended to consider all orientations ((two axes, (the third being the electron beam path). The thesis of one student, Salzman, was based on work in this area.

A particularly striking discovery in the hemoglobin work was the demonstration of the presence of a "bracelet" protein which is implicated in maintaining the integrity of the quaternary structures of these molecules. These subunits, which contain no heme prosthetic groups, form a bracelet, or torroid, upon which the remaining subunits bind. The hexagonal bilayer appearance of these giant proteins have an absolute requirement for the presence of these "linker" subunits. STEM examinations of preparations depleted of this subunit showed no hexagonal bilayer structures in the general field of view.

Several ancillary techniques were developed as a result of the presence of an IBM 4381 super-mini mainframe in the lab starting in the early 1980s. This essentially unlimited access to reasonable fast (by present standards) computational power allowed us the luxury of algorithm exploration on a scale that would have not been attempted if we were required to pay for compute cycles. One example has already been mentioned and that is our development of $3 \mathrm{D}$ reconstruction algorithms for use with STEM 
projection image data. Another example is the development of a technique to compute the stoichiometry of a multisubunit protein using a linear equations approach. We were able to demonstrate that the subunit stoichiometry of a protein can be calculated if the amino acid analysis is known for each isolated subunit and also the intact molecule. Expressed as a series of linear equations, (subunit coefficients on the left hand and the intact molecule analysis on the right hand of the equation) a least squares solution will provide values for this overdetermined set of equations ( 20 amino acids $=20$ equations, ususally in four or less unknowns) which agree very closely with known values and provide reasonable stoichiometries for the unknown ratios of the invertebrate hemoglobins. This problem is not trivial because the hemoglobins of many annelid hemoglobins contain approx. 200 copies of anywhere from 3 to 7 different subunits.

Over the past several years we have been recognized as leaders in the field of invertebrate hemoglobin structure and function. In the last year Vinogradov and Kapp were the editors of a volume of papers that were the results of a meeting on the subject of the structure and function of the invertebrate respiratory proteins.

In work closely allied to the study of protein structures we have developed a fairly extensive library of subroutines for examination of protein crystal structure and sequence alignment. Specifically we rewrote the Needleman and Wunsch dynamic programming technique from FORTRAN into APL so that we could easily modify the interpreted code "on the fly". This work has allowed us to more closely relate the results of STEM examination of biological macromolecules with the growing list of crystal structures contained in the Brookhaven database. Recently we have begun to simulate STEM images using the Brookhaven coordinates in an attempt to obtain a better understanding of radiatior damage, orientation classification, and substrate effects in experimental STEM im ges. 


\section{Reference Groups}

- (Papers and Abstracts in Bibliography)

A. (Construc- Papers 26,27,38,42,39 tion)

\begin{tabular}{|c|c|c|}
\hline & Abstracts & 36,34 \\
\hline \multirow{2}{*}{$\begin{array}{l}\text { B. (Field Emis- } \\
\text { sion) }\end{array}$} & Papers & 41,31 \\
\hline & Abstracts & $32,35,51$ \\
\hline \multirow[t]{2}{*}{$\begin{array}{l}\text { C. (STEM of } \\
\text { Atoms) }\end{array}$} & Papers & $\begin{array}{l}37,43,46,65,66,67,68,70,73,74,90,98 \\
105,107,110,124,160,203,211 \\
215,238,248,254\end{array}$ \\
\hline & Abstracts & $\begin{array}{l}33,49,50,53,55,56,59,61,62,75,76,77, \\
80,81,91,92,93,96,99,100,101, \\
129,132,146,134,142,163,166,167, \\
179,182,186,193,197,217,244,252, \\
260,261,263,265\end{array}$ \\
\hline \multirow[t]{2}{*}{ D. (SEM) } & Papers & $54,57,69,71,72,97$ \\
\hline & Abstracts & $44,52,58,60,78,64,176$ \\
\hline \multirow{2}{*}{$\begin{array}{l}\text { E. (Energy } \\
\text { Loss) }\end{array}$} & Papers & $87,89,106,108,150,156,159,162,245$ \\
\hline & Abstracts & $\begin{array}{l}84,85,102,103,115,116,120,175,177, \\
178,180,191,195,144,171\end{array}$ \\
\hline \multirow{2}{*}{$\begin{array}{l}\text { F. (Secondar- } \\
\text { ies) }\end{array}$} & Papers & 206 \\
\hline & Abstracts & 138 \\
\hline \multirow[t]{2}{*}{ G. (DNA) } & Papers & - \\
\hline & Abstracts & $82,83,104,133$ \\
\hline \multirow{2}{*}{$\begin{array}{l}\text { H. } \\
\text { (Nucleosomes) }\end{array}$} & Papers & $\cdot$ \\
\hline & Abstracts & $154,185,233$ \\
\hline
\end{tabular}




\begin{tabular}{lll} 
I. $\left(C_{s}\right)$ & Papers & $\begin{array}{l}198,286,302,319,280,367,372,373, \\
503,504\end{array}$ \\
& & $45,95,137,181,187,192,196,285,298$, \\
& Abstracts & 201 \\
\hline J. & & $282,325,353,464$ \\
(Optimisation) & Papers & $291,296,297,306$ \\
\hline & Abstracts & $208,209,214,221$ \\
\hline K. (Theory) & Papers & $239,272,279,283,287,384,420,422$, \\
& & $423,425,430,431,432,437,439,461$ \\
& Abstracts & $398,417,418,419,459,460$ \\
\hline L. (lmage Pro- & Papers & $308,322,448$ \\
cessing) & & $313,294,316,320,326,329,365,381$, \\
& A.ostracts & 385 \\
\hline M. (3D Recon- & Papers & $207,346,347,357,371,375,392,393$, \\
struction) & & $304,396,429,462,473,474$ \\
& Abstracts & $113,355,356,358,379,400,403$ \\
\hline N. (Hernoglo- & Papers & $321,327,337,338,339,347,348,349$, \\
bin Work) & & $357,363,370,377,382,383,392$, \\
& & $393,394,396,404,411,421,427,429$, \\
& & $443,444,466,467,468,473,474,488$, \\
& & $389,390,491,494,495,498,503$ \\
& & $300,307,312,314,318,324,334,356$, \\
& & $358,359,360,361,362,364,365$, \\
& & $378,379,380,381,386,387,395,413$, \\
& & $414,415,426,440,441,442,445,446$, \\
& & $457,458,459,463,464,465,479,480$, \\
& & $481,482,483,484,4961,497$ \\
& &
\end{tabular}




\section{Crewe Laboratory Publications}




\section{Bibliography}

1951-59

1. A.V. Crewe and A.E. Litherland, The Effects of Geometry on Scattering Distributions in the Wilson Cloud Chamber, J. Sci. Inst. 28 (1951) p. 182 .

2. A.V. Crewe, The Multiple Scattering of $\mu$ Mesons, Proc. Phys. Soc. 64 (1951) p. 660.

3. A.V. Crewe and W.H. Evans, The Diffusion Cloud Chamber, Atomics 3 (1952) p. 221.

4. A.V. Crewe and A. Ashmore, The Multiple Scattering of 7.5 Mev Deuterons in Metals, Proc. Phys. Soc. 66 (1953) p. 1172.

5. A.V. Crewe, M.H. Alston, W.H. Evans, L.L. Green, and J.G. Wilmott, The Scattering of $17.5 \mathrm{Mev}$ Neutrons in Helium, Proc. Phys. Soc. 67 (1954) p. 657.

6. A.V. Crewe, H.M. Alston, and W.H. Evans, A Stereoscopic Reprojection Apparatus for Neutron Scattering Experi- ments, J. Sci. Inst. 31 (1954) p. 252.

7. A.V. Crewe, M.H. Alston, and W.H. Evans, Some Practical Aspects of Diffusion CloudChamber Operation, Rev. Sci. Inst. 25 (1954) p. 547.

8. A.V. Crewe and K.I. LeCouteur, The Extracted Proton Beam of the Liverpool Synchrocyclotron, Rev. Sci. Inst. 26 (1955) p. 725.

9. A.V. Crewe, Beam Extraction from the Liverpool Synchrocyclotron, Proc. Roy. Soc. 232 (1955) p. 242.

10. A.V. Crewe and U.E. Kruse, Regenerative Beam Extraction on the Chicago Synchrocyclotron, Rev. Sci. Inst. 27 (1956) p. 5.

11. A.V. Crewe, Pion Production in the Pion-Nucleon Collisions at $240 \mathrm{Mev}$, Bull. Amer. Phys. Soc. 1 (1956) p. 276.

12. A.V. Crewe, Beam Extraction on Weak Focusing Machines, 
Proc. CERN Symposium 1 (1956) p. 141.

13. A.V. Crewe, M.H. Alston, W.H. Evans and F. von Gierke, Positive Pion Production in Proton-Proton Collisions at 383 Mev, Proc. CERN Symposium 1 (1956) p. 334.

14. A.V. Crewe, M.H. Alston, W.H. Evans and F. von Gierke, A Study of Positive Pion Production in Proton-Proton Collision at $383 \mathrm{Mev}$, Proc. Phys. Soc. 69 (1956).

15. A.V. Crewe and Stanley Cohen, Regenerative Action in High Energy Accelerators, Nuclear Instruments 1 (1957) p. 31.

16. A.V. Crewe, U.E. Kruse, R.H. Miller and L.G. Pondrom, Search for Asymmetries in the Scattering and Decay of Pions, Phys. Rev. 108 (1957) p. 1531.

17. A.V. Crewe, L.G. Pondrom and U.E. Kruse, $\pi^{+}$Production in Hydrogen by $450 \mathrm{Mev}$ Protons, Bull. Amer. Phys. Soc. 3 (1958) p. 196.

18. A.V. Crewe, Magnetic Spectrometer for $1 \mathrm{Bev} / \mathrm{c}$ Momentum, Bull. Amer. Phys. Soc. 3 (1958) p. 333.

19. A.V. Crewe, Magnetic Spectrometer for $450 \mathrm{Mev}$ Protons,
Rev. Sci. Inst. 29 (1958) pp. 880-84.

20. A.V. Crewe, E. Garwin, B. Ledley, E. Lillethun, R. March and $\mathbf{S}$. Marcowitz, Charge Independence in the Reactions $\rho$ $+d \rightarrow \pi^{0}+\mathrm{He}^{3}$ and $\rho+d$ $\rightarrow \pi^{+}+H^{3}$ at $450 \mathrm{Mev}$, Phys. Rev. Letters 2 (1959) pp. 269-270.

21. A.V. Crewe, B. Ledley, E. Lillethun, S. Marcowitz, and L.G. Pondrom, Elastic ProtonDeuteron Scattering at 450 Mev, Phys. Rev. 114 (1959) pp. 1361-65.

22. A.V. Crewe, Notes on External Particle Beams from the Argonne 12.5 Bev Synchrotron, Proc. Int'l Conf. on HighEnergy Accelerators and Instrumentation CERN (1959).

23. A.V. Crewe, The Argonne Zero Gradient Synchrotron (ZGS), Proc. Int'l Conf. on HighEnergy Accelerators and Instrumentation CERN (1959).

\section{$1960-65$}

24. A.V. Crewe, B. Ledley, E. Lillethun, S. Marcowitz and C. Rey, Charge Independence in the Reactions $\rho+d \rightarrow \pi^{0}+$ $\mathrm{He}^{3}$ and $\rho+d \rightarrow \pi^{+}+H^{3}$ at $450 \mathrm{Mev}$, Phys. Rev. 118 (1960) p. 1091. 
25. Y. Nambu and G. Jona-Lasinio, Dynamical Model of Elementary Particles Based on an Analogy with Superconductivity. Il, Phys. Rev. 124 (1961) pp. 246-254.

26. A.V. Crewe, A New Kind of Scanning Microscope, Journal de Microscopie 2 (1963) p. 369.

27. A.V. Crewe, Scanning Techniques for High Voltage Microscopes, Proc. AMU-ANL High Voltage Electron Microscope Mtg. (Argonne National Laboratory, 1964) pp. 68-81.

28. A.V. Crewe and J.J. Katz, Nuclear Research U.S.A., New York: Dover Publishers Inc. (1964).

29. A.V. Crewe and J.J. Katz, Research U.S.A., New York: McGraw Hill Book Co. (1964).

30. A.V. Crewe, R.D. George, L.G. Ratner and L.C. Teng, Experimental Area Beams from the ANL 12.5 Bev Proton Synchrotron, Bull. Amer. Phys. Soc. 10 (1965) p. 654.

31. A.V. Crewe, Some Effects of Quadrupole Misalignments in a Microscope, AMU-ANL High Voltage Electron Microscope Vewsletter, July 6 (1965).

$1966-6 ?$
32. J.W. Butler, Digital Computer Techniques in Electron Microscopy, Proc. 6th Int'l Congress for Electron Microscopy (Kyoto, 1966) p. 191.

33. A.V. Crewe, Energy Loss Techniques in a Scanning Microscope, Proc. 6th Int'l Congress for Electron Microscopy (Kyoto, 1966) p. 635.

34. A.V. Crewe, Experiments with Quadrupole Lenses in a Scanning Microscope, Proc. 6th Int'l Congress for Electron Microscopy (Kyoto, 1966) p. 627.

35. A.V. Crewe, Experiments with a Field Emission Electron Gun, Proc. 6th Int'l Congress for Electron Microscopy (Kyoto, 1966) p. 629.

36. A.V. Crewe, A Transmission Scanning Microscope, Proc. 6th Int'l Congress for Electron Microscopy (Kyoto, 1966) p. 631.

37. A.V. Crewe, Scanning Electron Microscopes: Is High Resolution Possible?, Science 154 (1966) pp. 729-738.

38. A.V. Crewe, J.W. Butler and L.M. Welter, A ComputerControlled Electron Microscope System, Proc. Roy. Microsc. Soc. MICRO 67 (1967). 
39. A.V. Crewe, D.N. Eggenberger, L.M. Welter and J. Wall, Experiments with Quadrupole Lenses in a Scanning Microscope, J. Appl. Phys. 38 (1967) pp. 4257-66.

40. A.V. Crewe, Science and the War on ..., Physics Today 20 (1967) pp. 25-30.

41. A.V. Crewe, D.N. Eggenberger, J. Wall and L.M. Welter, Electron Gun Using a Field Emission Source, Rev. Sci. Inst. 39 (1968) pp. 576-83.

42. R.N. Lewis, E.A. Jung, L.M. Welter, L.S. Van Loon and G.L. Chapman, Flexible High Voltage Supply for Experimental Electron Microscope, Rev. Sci. Instr. 39 (1968) pp. 1522-26.

43. A.V. Crewe, J. Wall and L.M. Welter, A High Performance Transmission Scanning Microscope, Fourth European Regional Conference on Electron Microscopy (Rome, 1968) p. 7.

44. A.V. Crewe, M. Isaacson and D. Johnson, A Simple Scannin/s Microscope of Medium Performance, Fourth European Regional Conference on Electron Microscopy (Rome, 1968) p. 75.

45. A.V. Crewe, D. Cohen and P. Meads, A Multipole Element for the Correcting of Spherical
Aberration, Fourth European Regional Conference on Electron Microscopy (Rome, 1968) p. 183.

46. A.V. Crewe, J. Wall and L.M. Welter, A High-Resolution Scanning Transmission Electron Microscope, J. Appl. Phys. 39 (1968) pp. 5861-68.

47. L.M. Welter, A.N. Stroud and D.L. Resh, Scanning Energy Analyzing Microscopy of Chromosomes, Biophys. Soc. $A b$ stracts, 12th Ann. Mtg. (1968).

48. A.P. MacKenzie, FreezeDehydration for the Scanning Electron Microscope, Biophys. Soc. Abstracts, 12th Ann. Mtg. (1968) p. A190.

49. A.V. Crewe, J. Wall and L.M Welter, A High Resolution Scanning Microscope, Proc. 26th Ann. EMSA Mtg. (1968).

50. A.V. Crewe, The Potentials of Scanning Microscopy, Proc. 26th Ann. EMSA Mtg. (1968) p. 352.

51. A.V. Crewe and M. Isaacson, The Use of Field Emission Tips in a Scanning Microscope, Proc. 26th Ann. EMSA Mtg. (1968).

52. A.V. Crewe, D. Johnson and M. Isaacson, An Electron Gun 
Scanning Microscope, Proc. 26th Ann. EMSA Mtg. (1968).

53. M.G.R. Thomson and A.V. Crewe, The Possibility of Improving Scanning Microscope Images by After-Treatment, Proc. 26th Ann. EMSA Mtg. (1968).

54. A.V. Crewe, M. Isaacson and D. Johnson, A Simple Scanning Electron Microscope, Rev. Sci. Inst. 40 (1969) pp. 241-46.

55. A.V. Crewe, High Resolution Scanning Electron Microscopy, Proc. 2nd Ann. Scanning Microscope Symposium (IIT Research Institute, 1969) p. 11.

56. A.V. Crewe, Closing the Gap--A $5 \AA$ Scanning Microscope, Proc. 27th Ann. EMSA Mtg. (1969) p. 6.

57. A.V. Crewe, M. Isaacson and D. Johnson, A High Performance Energy Analyzer for Use in Electron Scanning Microscopy, Proc. 27th Ann. EMSA. Mtg. (1969) p. 14.

58. A.V. Crewe, M. Isaacson and D. Johnson, Secondary Electron Detection in a Field Emission Scanning Microscope, Proc. 27th Ann. EMSA Mtg. (1969) p. 16.
59. A.V. Crewe and J. Wall, Scanning Microscopy of Thin Biological Specimens, Proc. 27th Ann. EMSA Mtg. (1969) p. 48.

60. D. Johnson and P. Morieraty, Examination of Schistosome Cercariae and Schistosomules by Scanning Electron Microscopy, Proc. 27th Ann. EMSA Mtg. (1969) p. 50.

61. E. Zeitler and M.G.R. Thomson, The Theoretical Contrast in Scanning and Conventional High Resolution Microscopes, Proc. 27th Ann. EMSA Mtg. (1969) p. 170.

62. A.V. Crewe and J. Wall, High Resolution Scanning Microscopy, Proc. 27th Ann. EMSA Mtg. (1969) p. 172.

63. A.N. Stroud, L.M. Welter, D.A. Resh, D.A. Habeck, A.V. Crewe and J. Wall, Scanning Electron Microscopy of Cells, Science 164 (1969) pp. 830-32.

1970

64. J.V. Smith, A.T. Anderson, R.C. Newton, E.J. Olsen, P.J. Wyllie, A.V. Crewe, M.S. Isaacson and D. Johnson, Petrologic History of the Moon Inferred from Petrography, Mineralogy and Petrogenesis of Apollo 11 Rocks, Proc. Apollo 
11 Lunar Sci. Conf. 1 (1970) pp. 897-925.

65. A.V. Crewe, High Resolution Scanning Microscopy of Biological Specimens, Berichte der Bunsen-Gesell. fur Phys. Chem. 74 (1970) pp. 1181-87.

66. E. Zeitler and M.G.R. Thomson, Scanning Transmission Electron Microscopy. I, Optik 31 (1970) pp. 258-80.

67. E. Zeitler and M.G.R. Thomson, Scanning Transmission Electron Microscopy. II, Optik 31 (1970) pp. 359-66.

68. A.V. Crewe and J. Wall, Contrast in a High Resolution Scanning Electron Microscope, Optik 30 (1970) pp. 461-74.

69. A.V. Crewe, M. Isaacson and D. Johrison, Secondary Electron Detection in a Field Emission Scanning Microscope, Rev. Sci. Inst. 41 (1970) pp. 20-24.

70. A.V. Crewe, The Current State of High Resolution Scanning Electron Microscopy, Quarterly Reviews of Biophysics 3 (1970) pp. 1-39.

71. A.T. Anderson, A.V. Crewe, J.R. Goldsmith, P.B. Moore, J.C. Newton, E.J. Olsen, J.V. Smith and P.J. Wyllie, Petrologic History of the Moon Sug- gested by Petrography, Mineralogy and Crystallography, Science 167 (1970) p. 587.

72. A.V. Crewe, M. Isaacson, D. Johnson and J.V. Smith, Scanning Electron Microscopy of Lunar Spherules, Geochimica et Cosmochimica Acta 34 (1970).

73. A.V. Crewe, Field Emission and an Electron Gun, Microscope Design Using Field Emission and Con irast Mechanisms in a High Resolution Scanning Microscope, Lectures presented at Centre for Scientific Culture (Erice, Sicily, 1970).

74. A.V. Crewe, J. Wall and J. Langmore, Visibility of Single Atoms, Science 168 (1970) pp. 1338-40.

75. A.V. Crewe, J. Langmore and J. Wall, High Resolution Capabilities in Scanning Microscopy, Proc. 7th Int'l Congress Electron Microscopy 1 (Grenoble, 1970).

76. A.V. Crewe and J. Wall, Contrast M thods in a High Resolution Scanning Microscope--the Use of Multiple Detectors, Proc. 7th Int'l Congress Electron Microscopy 1 (Grenoble, 1970) p. 35.

77. M.G.R. Thompson and E. Zeitler, Phase Contrast in the Scanning Transmission Elec- 
tron Microscope, Proc. 7th Int'l Congress Electron Microscopy 1 (Grenoble, 1970) p. 63.

78. A.V. Crewe, M. Isaacson and D. Johnson, A Simple MultiPurpose Scanning Microscope, Proc. 7th Int'l Congress Electron Microscopy 1 (Grenoble, 1970) pp. 209-210.

79. A.V. Crewe, J. Wall and J. Langmore, High Resolution Scanning Electron Microscopy of Nucleic Acid Salts, Proc. 7th Int'l Congress Electron Microscopy 1 (Grenoble, 1970) pp. 467-68.

80. A.V. Crewe, J. Wall and J. Langmore, Single Atom Visibility, Proc. 7th Int'l Congress Electron Microscopy 1 (Grenoble, 1970) pp. 485-86.

81. A.V. Crewe, J. Langmore, J. Wall and M. Beer, Single Atom Contrast in a Scanning Microscope, Proc. 28th Ann. EMSA Mtg (1970) pp. 250-51.

82. J. Wall and J. Langmore, Studies of DNA Using a $5 \AA$ Scanning Microscope, Proc. 28th Ann. EMSA Mtg. (1970) pp. 252-53.

83. J. Langmore and J. Wall, Conformational Study of tRNA, Using the High Resolution Scanning Electron Microscope,
Proc. 28th Ann. EMSA Mtg. (1970) pp. 254-55.

84. A.V. Crewe, M. Isaacson and D. Johnson, Electron Beam Damage in Biological Molecules, Proc. 28th Ann. EMSA Mtg. (1970) pp. 264- 55.

85. A.V. Crewe, M. Isaacson and D. Johnson, The Energy Loss of $20 \mathrm{KEV}$ Electrons in Biological Molecules, Proc. 28th Ann. EMSA Mtg. (1970).

86. A.V. Crewe and J. Saxon, Interference Experiments with a Field Emission Source, Proc. 28th Ann. EMSA Mtg. (1970).

1971

87. A.V. Crewe, M. Isaacson and D. Johnson, Electron Energy Loss Spectra of the Nucleic Acid Bases, Nature 231 (1971) pp. 262-63.

88. A.V. Crewe, High Resolution Scanning Microscopy of Biological Specimens, Phil. Trans. Roy. Soc. 261 (London, 1971) pp. 61-70.

89. A.V. Crewe, M. Isaacson and D. Johnson, A High Resolution Electron Spectrometer for Use in Transmission Scanning Electron Microscopy, Rev. Sci. Inst. 42 (1971) pp. 411-20. 
90. A.V. Crewe, A High Resolution Scanning Electron Microscope, Scientific American 224 (1971) pp. 26-35.

91. E. Zeitler, Scanning Transmission Electron Microscopy, Proc. 4th Ann. SEM Symposium (IIT Research Institute, 1971) pp. 25-31.

92. A.V. Crewe, A $100 \mathrm{Kv}$ Transmission Scanning Microscope, Proc. 29th Ann. EMSA Mtg. (1971).

93. A.V. Crewe and J. Wall, Quantitative Analysis in High Resolution Transmission Scanning Microscopy, Proc. 29th Ann. EMSA Mtg. (1971).

94. A.V. Crewe and V. Beck, A New Color Display System for Scanning Transmission Microscopes, Proc. 29th Ann. EMSA Mtg. (1971).

95. A.V. Crewe and J. Saxon, Electron Holography and the Correction of Spherical Aberration, Proc. 29th Ann. EMSA Mtg. (1971).

96. A.V. Crewe, Production of Electron Probes a Few $\AA$ in Diameter, Proc. 7th Nat'l Conf. on Electron Probe Analysis (1971).

97. J.B. Sheffield, M. Isaacson and D. Johnson, Visualization of
Surface Structures on Embryonic Cells with a Simple Electron Gun Scanning Microscope, Experimental Cell Research 64 (1971) pp. 49-56.

98. A.V. Crewe, "High Intensity Electron Sources and Scanning Electron Microscopy", Electron Microscopy in Material Science, New York: Academic Press (1971), pp. 162-207.

1972

99. A.V. Crewe and M. Retsky, Single Atom Visibility, Proc. 30th Ann. EMSA Mtg. (1972).

100. A.V. Crewe and E. Zeitler, A $100 \mathrm{Kv}$ High Resolution Scanning Transmission Microscope, Proc. 30th Ann. EMSA Mtg. (1972).

101. A.V. Crewe, Imaging of Single Atoms in Scanning Microscopy, Proc. 30th Ann. EMSA Mtg. (1972).

102. A.V. Crewe, M. Isaacson and D. Johnson, Characteristic Energy Loss of Fast Electrons in Biological Materials, Biophys. Soc. Abstr. 16th Ann. Mtg. (1972) p. 48a.

103. A.V. Crewe, M. Isaacson and D. Johnson, Implications of Electron Beam Damage in Electron Microscopy, Biophys. Soc. 
Abstr. 16th Ann. Mtg. (1972) p. 49a.

104. A.V. Crewe, N.R.Cozzarelli, J. Wall and J.P. Langmore, Development of DNA BaseSpecific Stains for Electron Microscopy, Biophys. Soc. Abstr. 16th Ann. Mtg. (1972) p. 52a.

1973

105. A.V. Crewe (E. Wolf, Ed.), "Production of Electron Probes Using a Field Emission Source", Progress in Optics XI, North Holland: Braunschweig (1973) pp. 223-246.

106. M. Isaacson, D. Johnson and A.V. Crewe, Electron Beam Excitation and Damage of Biological Molecules; Its Implications for Specimen Damage in Electron Microscopy, Rad. Res. 55 (1973) pp. 205-224.

107. J.P. Langmore and J. Wall, The Collection of Scattered Electrons in Dark Field Electron Microscopy, Optik 38 (1973) pp. 335-350.

108. A.V. Crewe, Considerations of Specimen Damage for the Transmission Electron Microscope, Conventional Versus Scanning, J. Mol. Biol. 80 (1973) pp. 315-25.
109. D. Johnson and M.S. Isaacson, Cytosine Reflectance Measurements Using Electron Energy Loss Spectra and Synchrotron Radiation, Optics Communications 8 (1973) pp. 406-08.

110. J. Wall, Development of the High Resolution Scanning Transmission Microscope, Scanning Electron Microscopy (1973) pp. 158-163.

111. J. Langmore, J. Wall, $M$. Isaacson and A.V. Crewe, Carbon Support Films for High Resolution Electron Microscopy, Proc. 31st Ann. EMSA Mtg. (1973) pp. 76-77.

112. J. Wall, J. Langmore, $M$. Isaacson and A.V. Crewe, Resolution Attainable with the Present Day STEM, Proc. 31st Ann. EMSA Mtg. (1973) pp. 230-31.

113. M. Isaacson, J. Langmore, J. Wall and A.V. Crewe, Inelastic Scattering in Electron Microscopy, Proc. 31st Ann. EMSA Mtg. (1973) pp. 254-55.

114. E. Zeitler, Reconstruction of Objects from their Projections Using Orthogonal Functions, Proc. 31st Ann. EMSA Mtg. (1973) pp. 268-69.

115. D.E. Johnson and M. Isaacson, Low Z Elemental Analysis Us- 
ing Energy Loss Electrons in a Scanning Microscope, Proc. 31st Ann. EMSA Mtg. (1973) pp. 290-91.

116. M. Isaacson, Inelastic Scattering and Beam Damage of Biological Molecules, Proc. 31st Ann. EMSA Mtg. (1973) pp. 478-79.

117. M.K. Lamvik, M.S. Isaacson and A.V. Crewe, Studies of Aggregates of Two Muscle Proteins with Scanning and Conventional Transmission Electron Microscopy, Proc. 31st Ann. EMSA Mtg. (1973) pp. 600-01.

118. A.V. Crewe, J. Langmore, J. Wall and M. Isaacson, Scanning Transmission Electron Microscopy at High Resolution, Proc. 31st Ann. EMSA Mtg. (1973).

119. V. Beck, Slow Scan Display System for a Scanning Electron Microscope, Rev. Sci. Inst. 44 (1973) pp. 1064-66.

\section{4}

120. M. Isaacson, Characteristic Energy Loss of Electrons in Biological Materials, Proc. 4th Int'l Conf. on YUV Phys. (Hamburg, 1974).

121. H. Rose, Phase Contrast in Scanning Transmission Elec- tron Microscopy, Optik 39 (1974) pp. 416-36.

122. J. Wall, M. Isaacson and J.P. Langmore, The Collection of Scattered Electrons in Dark Field Electron Microscopy, Optik 39 (1974) pp. 359-74.

123. T.A. Roth, The Field Emitter: Electric Field Calculation, $J$. Applied Phys. 45 (1974) pp. 4771-73.

124. A.V. Crewe, Scanning Transmission Electron Microscopy, $J$. Microscopy 100 (1974) pp. 247-59.

125. A.V. Crewe and T. Groves, Thick Specimens in the CEM and STEM I. Contrast, $J$. $A p$ plied Phys. 45 (1974) pp. 3662-72.

126. J. Hainfeld and M. Isaacson, Human Red Cell Studies Using Scanning Electron Microscope, Proc. 32nd Ann. EMSA Mtg. (1974) pp. 162-63.

127. M.K. Lamvik, J.M. Pullman and A.V. Crewe, Unstained Biological Specimens in High Resolution Electron Microscopy, Proc. 32nd Ann. EMSA Mtg. (1974) pp. 234-35.

128. S. Panem, P.S.D. Lin, A.V. Crewe and W.H. Kirsten, Scanning Electron Microscopy of 
Murine Oncornavirus Infected Cells, Proc. 32nd Ann. EMSA Mtg. (1974) pp. 252-53.

129. A.V. Crewe, The High Resolution Scanning Transmission Electron Microscope, Proc. 32nd Ann. EMSA Mtg. (1974) pp. 316-17.

130. E. Zeitler and M. Isaacson, Simplified Calculation of Phase Contrast for Finite Detector and Illumination Angles, Proc. 32nd Ann. EMSA Mtg. (1974) pp. 370-71.

131. A.V. Crewe and V. Beck, Resolution Limits Imposed by Specimen-Electron Interactions, Proc. 32nd Ann. EMSA Mtg. (1974) pp. 372-73.

132. M. Isaacson, J. Langmore and H. Rose, Mearivements of the Non-Local Nature of the Inelastic Scattering of Electrons in Carbon, Proc. 32nd Ann. EMSA Mtg. (1974) pp. 374-75.

133. J.P. Langmore and A.V. Crewe, Progress Towards the Sequencing of DNA by Electron Microscopy, Proc. 32nd Ann. EMSA Mig. (1974) pp. 376.77.

134. J.P. Langmore, M.S. Isaacson and A.V. Crewe, The Study of Single Heavy Atom Motion in the STEM, Proc. 32nd Ann. EMSA Mtg. (1974) pp. 378-79.
135. J. Munch and E. Zeitler, Interference Experiments with a Field Emission Electron Microscope, Proc. 32nd Ann. EMSA Mtg. (1974) pp. 386-87.

136. T.A. Roth, J. Munch and E. Zeitler, The Effect of TopAnode Distance on Field Emission Current, Proc. 32nd Ann. EMSA Mtg. (1974) pp. 420-21.

137. A.V. Crewe and V. Beck, A Quadrupole-Octupole Corrector for a $100 \mathrm{KEV}$ STEM, Proc. 32nd Ann. EMSA Mtg. (1974) pp. 426-27.

138. D. Voreades and A.V. Crewe, Correlation Between Inelastic Electron Scattering and Secondary Electron Production, Proc. 32nd Ann. EMSA Mtg. (1974) pp. 428-29.

139. T. Groves and A.V. Crewe, The Use of Thick Specimens in a STEM, Proc. 32nd Ann. EMSA Mtg. (1974) pp. 550-51.

140. P.S.D. Lin, On Some Testing Specimens for High Resolution SEM, Proc. 32nd Ann. EMSA Mtg. (1974) pp. 556-57.

141. M.K. Lamvik and S.D. Lin, A New Specimen Mounting System for Scanning Electron Microscopy, J. Microsc. 101 (1974) pp. 329-31. 
142. A.V. Crewe, J. Langmore, M. Isaacson and M. Retsky, Understanding Single Atoms in the STEM, Proc. 8th Int'l Congress on Electron Microscopy (Canberra, 1974).

143. A.V. Crewe, J. Langmore, $M$. Lamvik and J. Pullman, Scanning Electron Microscopy of Unstained and Selectively Stained Biological Specimens, Proc. 8th Int'l Congress on Electron Microscopy (Canberra, 1974).

144. A.V. Crewe and E. Zeitler, Radiation Damage and Energy Analysis in the STEM, Proc. 8th Int'l Congress on Electron Microscopy (Canberra, 1974).

145. E. Zeitler and A.V. Crewe, Design and Construction of a 1 MEV Scanning Microscope, Proc. 8th Int'l Congress on Electron Microscopy (Canberra, 1974) pp. 40-41.

146. A.V. Crewe, High Resolution Scanning Microscopy, Proc. 8th Int'l Congress on Electron Microscopy (Canberra, 1974).

147. A.V. Crewe and T. Groves, The Use of "Thick Specimens in the STEM and CEM, Proc. Sth Int'l Congress on Electron Microscopy (Canberra, 1974).
148. A.V. Crewe and P. Lin, Experience with High Resolution Scanning Electron Microscopes with Field Emission Sources, Proc. 8th Int'l Congress on Electron Microscopy (Canberra, 1974).

149. M. Isaacson and J.P. Langmore, Determination of the NonLocalization of the Inelastic Scattering of Electrons by Electron Microscopy, Optik 41 (1974) pp. 92-96.

150. S.D. Lin, Electron Radiation Damage of Thin Films of Glycine, Diglycine, and Aromatic Amino Acids, Rad. Res. 59 (1974) pp. 521-36.

151. M. Isaacson and J. Langmore, The Preparation and Observa. tion of Biological Specimens for the High Resolution Scanning Transmission Electron Microscope, Proc. 7th Ann. Scanning Electron Microscope Symposium (IIT Research Institute, 1974) pp. 19-26.

152. A. Beorchia and P. Bonhomme, Experimental Studies of Some Dampings of Electron Microscope Phase Contrast Transfer Function, Optik 39 (1974) pp. 437.442.

1975 
153. Shau-da-Lin and M.K. Lamvik, High Resolution Scanning Electron Microscopy at the Subcellular Level, J. Microsc. 103 (1975) pp. 249-57.

154. J.P. Langmore and J.C. Wooley, Chromatin Architecture: Investigation of a Subunit of Chromatin by Dark Field Electron Microscopy, Proc. Nat'l Acad. Sci.(USA) 72 (1975) pp. 2691-95.

155. A.V. Crewe, J. Langmore and M. Isaacson (B. Siegel and D.R. Beaman, Eds.), "Resolution and Contrast in the Scanning Transmission Electron Microscope," Physical Aspects of Electron Microsiopy and Microbeam Analysis, New York: John Wiley \& Sons (1975), pp. 47-62.

156. M.S. Isaacson (B. Siegel and D.R. Beaman, Eds.), "Inelastic Scattering and Beam Damage of Biological Molecules," Physical Aspects of Electron Microscopy and Microbeam Analysis, New York: John Wiley \& Sons (1975), pp. 247-58.

157. P.S.D. Lin and R.P. Becker, Detection of Backscattered Electrons with High Resolution, Proc. of the Ann. S sapning Electron Microscop: Symposium (IIT Research Institute, 1975) pp. 61-70.
158. T. Groves and M.K. Lamvik, The Measurement of Signal Intensities for Thick Specimens in the STEM, Proc. of the Ann. Scanning Electron Microscope Symposium, IIT Res. Institute (1975) pp. 79-83.

159. A.V. Crewe and M. Isaacson, Electron Microspectroscopy, Ann. Rev. of Biophys. and Bioeng. 4 (1975) pp. 165-184.

160. A.V. Crewe, Electron Microscopes Using Field Emission Source, Surf. Sci. 48 (1975) pp. 152-160.

161. T. Groves, Thick Specimens in thie CEM and STEM, Ultramicroscopy 1 (1975) pp. 15-31.

162. M. Isaacson and D. Johnson, The Microanalysis of Light Elements Using Transmitted Energy Loss Electrons, Ultramicroscopy 1 (1975) pp. 33-52.

163. V. Beck and A.V. Crewe, High Resolution Imaging Properties of the STEM, Ultramicroscopy 1 (1975) pp. 137-44.

164. M. Ohtsuki and E. Zeitler, Minimal Beam Exposure with a Field Emission Source, Ultramicroscopy 1 (1975) pp. 163-65. 
165. T. Groves, Plural Scattering and Thick Specimens in Transmission Electron Microscopy, Ultramicroscopy 1 (1975) pp. 170-72.

166. A.V. Crewe, High Resolution Scanning Microscopy--What Next?, Proc. 33rd Ann. EMSA Mtg. (1975) pp. 18-19.

167. N.W. Parker, M. Isaacson and J.P. Langmore, Studies of the Adsorption and Diffusion of Single Heavy Atoms on Light Element Substrates Using the STEM, Proc. 33rd Ann. EMSA Mtg. (1975) pp. 104-05.

168. P.S.D. Lin and M.K. Lamvik, A Simple Transmission Stage for a Scanning Electron Microscope, Proc. 33rd Ann. EMSA Mtg. (1975) pp. 134-35.

169. P.S.D. Lin, On the Contrast of High Resolution Backscattered Electron Images, Proc. 33rd Ann. EMSA Mtg. (1975) pp. 206-07.

170. P.S.D. Lin and A.V. Crewe, Simultaneous Study of Both the Surface and Interior Structure of Biological Specimens in a Scanning Electron Microscope, Proc. 33rd Ann. EMSA Mtg. (1975) pp. 208-09.

171. D.E. Johnson and M. Isaacson, The Detection of Transmitted
Energy Loss Electrons for Elemental Analysis, Proc. 33rd Ann. EMSA Mtg. (1975) pp. 236-37.

172. M.K. Lamvik and A.V. Crewe, Mass Determination by Direct Measurement of Electron Scattering, Proc. 33rd Ann. EMSA Mtg. (1975) pp. 240.41.

173. D.E. Johnson, An Image Reconstruction System Applied to High Voltage Microscopy, Proc. 33rd Ann. EMSA Mtg. (1975) pp. 292-93.

174. M.K. Lamvik and S.D. Lin, An Improved Specimen Mount for Scanning Electron Microscopy, Proc. 33rd Ann. EMSA Mtg. (1975) pp. 132-33.

175. H. Hainfeld and M. Isaacson, Electron Energy Loss in Mernbrane Components: Possibilities of Contrast and Identification in the STEM, Proc. 33rd Ann. EMSA Mtg. (1975) pp. 506-07.

176. M.K. Lamvik, Scanning Secondary Electron Microscopy of Myofibrils Using Transmission Techniques, Proc. 33rd Ann. EMSA Mtg. (1975) pp. 556-57.

177. K. Ramamurti, A.V. Crewe and M. Isaacson, Low Temperature Beam Damage to Biological Specimens in the Electron Mi- 
croscope, Proc. 33rd Ann. EMSA Mtg. (1975) pp. 608-09.

178. M. Isaacson, J. Langmore, M. Lamvik, P. Lin, S. Golladay, J. Hainfeld, J. Pullman and D. Furlong, Mass Loss of Biological Molecules in the Electron Microscope, Proc. 33rd Ann. EMSA Mtg. (1975) pp. 676-77.

179. A.V. Crewe, Recent Developments and Future Prospects for STEM, Proc. EMAG Mtg. (Bristol, England, 1975) pp. 1-2.

180. K. Ramamurti, A.V. Crewe and $M$. Isaacson, Low Temperature Mass Loss of Thin Films of LPhenylalanine and $L$ Tryptophan Upon Electron Irradiation -- A Preliminary Report, Ultramicroscopy 1 (1975) pp. 156-58.

1976

181. N.W. Parker, S.D. Golladay and A.V. Crewe, A Theoretical Analysis of Third-Order Aberration Correction in the SEM and STEM, Proc. Scanning Electron Microscope Symposium (IIT Research Institute, 1976) pp. 37-44.

182. A.V. Crewe, Some Thoughts on the Future of the STEM, Proc. Sixth European Conf. on Electron Microscopy (1976) pp. 24-25.
183. M. Isaacson, The Potential of the High Resolution Scanning Transmission Electron Microscope in the Biological and Materials Science: Fact and Fiction, Proc. Sixth European Conf. on Electron Microscopy (1976) pp. 26-28.

184. J. Hainfeld, M. Isaacson and M. Sogard, The Use of Microspectroscopy in the STEM for the Identification of Membrane Components, Proc. Sixth European Conf. on Electron Microscopy (1976) pp. 30-31.

185. J. Langmore, Quantitative Studies of Unstained Biological Structures in the STEM, Proc. Sixth European Conf. on Electron Microscopy (1976) pp. 31-33.

186. A.V. Crewe, Design Trends in the STEM, Proc. Sixth European Conf. on Electron Microscopy (1976) pp. 65-66.

187. A.V. Crewe, V. Beck and N.W. Parker, Correction of Third Order Aberration in the STEM, Proc. Sixth European Conf. on Electron Microscopy (1976) pp. 322-23.

188. A.V. Crewe and E. Zeitler, A One Million Volt Scanning Microscopy: Progress Report, Proc. Sixth European Conf. on 
Electron Microscopy (1976) pp. 322-23.

189. J. Pullman and A.V. Crewe, Darkfield Microscopy of Unstained Specimens at High Beam Dosages, Proc. 34th Ann. EMSA Mtg. (1976) pp. 380-81.

190. M.K.

Lamvik, Electronmicroscopic Mass Determination Without a Densitometer: Quantitative Electron Microscopy Using Photographic Methods, Proc. 34th EMSA Mtg. (1976) pp. 380-81.

191. D.E. Johnson and M. Isaacson, Elemental Analysis of Thin Films Using Inner Shell Electron Energy Losses, Proc. 34th Ann. EMSA Mtg. (1976) pp. 414-15.

192. N.W. Parker, S.D. Golladay and A.V. Crewe, Third-Order Aberration Correction in the SEM and STEM, Proc. 34th Ann. EMSA Mtg. (1976) pp. 464-65.

193. M.S. Isaacson, D. Kopf, N.W. Parker and M. Utlaut, Some Observations on the Adsorption of Heavy Atoms on Carbon Substrates, Proc. 34th Ann. EMSA Mtg. (1976) pp. 498-99.

194. N.W. Parker, M. Utlaut and A.V. Crewe, Evaporative Cool- ing of High Current Density Mini-lenses, Proc. 34th Ann. EMSA Mtg. (1976) pp. 536-37.

195. K. Ramamurti, A.V. Crewe and M.S. Isaacson, Electron Beam Damage at Low Temperatures, Proc. 34th Ann. EMSA Mtg. (1976) pp. 554-55.

196. V. Beck and A.V. Crewe, Progress in Aberration Correction in the STEM, Proc. 34th Ann. EMSA Mtg. (1976) pp. 578-79.

197. M.S. Isaacson, D. Kopf, N.W. Parker and $M$. Utlaut, Observations of Surface Diffusion at the Atomic Level by Means of Microcinematography in the STEM, Proc. 34th Ann. EMSA Mtg. (1976) pp. 584-85.

198. A.V. Crewe and N.W. Parker, Correction of Third Order Aberrations in the Scanning Electron Microscope, Optik (1976) pp. 183-94.

199. A.V. Crewe, Very Low Voltage Electron Microscopy, Ultramicroscopy 1 (1976) pp. 267-69.

200. A.V. Crewe and P.S.D. Lin, The Use of Backscattered Electrons for Imaging Purposes in a Scanning Electron Microscope, Ultramicroscopy 1 (1976) pp. 231-38. 
201. N.W. Parker, S.D. Golladay and A.V. Crewe, A Theoretical Analysis of Third-Order Aberration Correction in the SEM and STEM, Proc. 9th Ann. Scanning Electron Microscope Symposium Part I (IIT Research Institute, 1976).

202. M.S. Isaacson and N.W. Parker, The Potential of Scanning Transmission Electron Microscopy for Studying Surface Phenomena on an Atomic Scale, Proc. 9th Ann. Scanning Electron Microscope Symposium Part II (IIT Research Institute, 1976) pp. 345-52.

203. M.S. Isaacson, J. Langmore, N.W. Parker, D. Kopf and M. Utlaut, The Study of the Adsorption and Diffusion of Heavy Atoms on Light Element Substrates by Means of the Atomic Resolution STEM, Ultramicroscopy 1 (1976) pp. 359-76.

204. M.K. Lamvik and T. Groves, Minimization of Dose as a Criterion for the Selection of Imaging Modes in Electron Microscopy of Amorphous Specimens, Ultramicroscopy 2 (1976) pp. 69-75.

205. M.S. Isaacson and J. Silcox, Report of a Workshop on Analytical Electron Microscopy,
Ultramicroscopy 2 (1976) pp. 89-104.

206. D. Voreades, Secondary Electron Emission from Thin Carbon Films, Surf. Sci. 60 (1976) pp. 325-48.

207. I. Lerche and E. Zeitler, Projections, Reconstructions and Orthogonal Functions, J. of Mathematical Analysis and Applications 56 (1976) pp. 634-49.

1977

208. A.V. Crewe, Post-Specimen Optics in the STEM: I. General Considerations, Optik 47 (1977) pp. 299-311.

209. A.V. Crewe, Post-Specimen Optics in the STEM: II. A Corrected Spectrometer, Optik 47 (1977) pp. 371-80.

210. G.E. Marsh, Accelerator System for 1-MV STEM, Rev. Sci. Inst. 48 (1977) pp. 841-43.

211. M. Isaacson, D. Kopf, J. Langmore, N.W. Parker and M. Utlaut, Abstract: Atomic Resolution Observations of HeavyAtom Adsorbates on LowAtomic-Number Substrates, $J$. Vac. Sci. Tech. 14 (1977) p. 434.

212. M.K. Lamvik and J.P. Langmore, Determination of Particle Mass Using Scanning 
Transmission Electron Microscopy, Scanning Electron Microscopy 1 (1977) pp. 401-09.

213. M. Ohtsuki and E. Zeitler, Young's Experiment with Electrons, Ultramicroscopy 2 (1977) pp. 147-48.

214. A.V. Crewe, Ideal Lenses and the Scherzer Theorem, Ultramicroscopy 2 (1977) $\mathrm{pp}$. 281-84.

215. M. Isaacson, D. Kopf, $M$. Utlaut, N.W. Parker and A.V. Crewe, Direct Observation of Atomic Diffusion by Scanning Transmission Electron Microscopy, Proc. Nat'l Acad. Sci. 74 (1977) pp. 1802-06.

216. M. Ohtsuki, S.L. White, E. Zeitler, T.E. Wellems, S.D. Fuller, M. Zwick, M.W. Makinen and P.B. Siegler, Electron Microscopy of Fibers and Discs of Hemoglobin $S$ Having Sixfold Symmetry, Proc. Nat'l Acad. Sci. 74 (1977) pp. 5538-42.

217. $M$. Isaacson, $D$. Kopf and $M$. Utlaut, Progress in Single Atom Microscopy, Proc. 35th Ann. EMSA Mtg. (1977) pp. 78-79.

218. M. Isaacson and M. Utlaut, Consiclerations on the Use of Electron and Photon Beams for Determining Micro-Chemical
Environment, Proc. 35th Ann. EMSA Mtg. (1977) pp. 240-41.

219. M.L. Collins and N.W. Parker, Preparation of Titanium Microgrids for Scanning Transmission Electron Microscopy, Proc. 35th Ann. EMSA Mtg. (1977) pp. 322-23.

220. M. Sogard and D. Deutsch, Observation of Human Low Density Lipoproteins in the STEM, Proc. 35th Ann. EMSA Mtg. (1977) pp. 472-73.

\section{8}

221. A.V. Crewe, Collision Broadening in Electron Beams, Optik $\mathbf{5 0}$ (1978) pp. 205-12.

222. $\mathrm{M}$. Isaacson and $\mathrm{M}$. Utlaut, $\mathrm{A}$ Comparison of Electron and Photon Beams for Determining Micro-Chemical Environment, Optik 50 (1978) pp. 213-34.

223. N.W. Parker, M. Utlaut and M.S. Isaacson, Design of Magnetic Spectrometers with Second-Order Aberrations Corrected, Optik 51 (1978) pp. 333-51.

224. M. Isaacson and R. Gomer, Extended Range Field Emission Spectroscopy, J. Appl. Phys. 15 (1978) pp. 253-56. 
225. M. Isaacson, All You Might Want to Know About ELS (But Are Afraid to Ask): A Tutorial, Scanning Electron Microscopy 1 (1978) pp. 763-76.

226. J. Orr, N. Toan, M. Ohtsuki, T. Wellems and R. Haselkorn, Glutamine Synthetase from Cyanobacterium Anabaena-7120, Federation Proceeding 37 (1978) p. 1431.

227. N.W. Parker, A.V. Crewe, M.S. Isaacson, W. Mankawich, A New Analytical Electron Microscope, 9th Int'l Congress on Electron Microscopy I (Toronto, 1978) pp. 18-19.

228. D. Kopf, M. Utlaut, A.V. Crewe, M. Isaacson and W. Mankawich, Some Instrumenta! Aspects of Single Atom Microscopy, 9th Int'l Congress on Electron Microscopy I (Toronto, 1978) pp. 20-21.

229. N.W. Parker, M. Utlaut and M. Isaacson, Magnetic Spectrometers with Corrected Second-order Aberration, 9th Int'l Congress on Electron Microscopy I (Toronto, 1978) pp. 20-21.

230. S. Golloday, Analysis of STEM Micrographs of Thick Objects, 9th Int'l Congress on Electron Microscopy II (Toronto, 1978) pp. 106-07.
231. D. Furlong, Use of the STEM to Obtain Information from One Level of a Complex Biological Object, 9 th Int'l Congress on Electron Microscopy II (Toronto, 1978) pp. 108-89.

232. M. Ohtsuki and M. Sogard, Observation of Biological Macromolecules Using Various Electron Microscopic Methods, 9th Int'l Congress on Electron Microscopy II (Toronto, 1978) pp. 170-71.

233. S. Usala, M. Isaacson and $T$. Martin, Scanning Transmission Electron Microscopy of Unstained Nucleosomes, 9th Int'l Congress on Electron Microscopy II (Toronto, 1978) pp. 170-71.

234. M. Isaacson, M.L. Collins, and M. Listvan, Electron Beam Damage of Biomolecules Assessed by Energy Loss Spectroscopy, 9 th Int'l Congress on Electron Microscopy III (Toronto, 1978) pp. 61-69.

235. A.V. Crewe, Is There a Future for the STEM?, 9th Int'l Congress on Electron Microscopy III (Toronto, 1978) pp. 197-204.

236. M.K. Lamvik, Muscle Thick Filament Mass Measured by Electron Scattering, J. Mol. Biol. 122 (1978) pp. 55-68. 
237. J. Hainfeld and M. Isaacson, The Use of Electron Energy Loss Spectroscopy or Studying Membrance Architecture: A Preliminary Report, Ultramicroscopy 3 (1978) pp. 87-95.

238. A.V. Crewe, Direct Imaging of Single Atoms and Molecules Using the STEM, Chemica Scripta 14 (1978-79) pp. 17-20.

239. A.V. Crewe, Some Space Charge Effects in Electron Probe Devices, Optik 52 (1978-79) pp. 337-46.

1979

240. A.V. Crewe, Direct Imaging of Single Atoms and Molecules Using the STEM, Chemica Scripta 14 (1978-79) pp. 17-20.

241. A.V. Crewe, Some Space Charge Effects in Electron Probe Devices, Optik $\mathbf{5 2}$ (1978-79) pp. 337-46.

242. D.G. Deutsch and M. Sogard, Observation of Human Low Density Lipoproteins in the STEM and FECTEM, Micron 10 (1979) pp. 25-28.

243. M. Isaacson, D. Kopf, M. Ohtsuki and M. Utlaut, Contamination as a Psychological Problem (Letter to the Editor),
Ultramicroscopy 4 (1979) pp. 101-104.

244. M. Isaacson, D. Kopf, M. Ohtuski and M. Utlaut, Atomic Imaging Using the Dark-Field Annular Detector in the STEM (Letter to the Editor), Ultramicroscopy 4 (1979) pp. 101-04.

245. M. Isaacson, Electron Beam Induced Damage of Organic Solids: Implications for Analytical Electron Microscopy, Ultramicroscopy 4 (1979) pp. 193-99.

246. D.M. Hwang, M. Utlaut, M.S. Isaacson, S.A. Solin and L. Minarski, Electron Energy Loss Studies of $C_{8} K$, Bull. Amer. Phys. Soc. 24 (1979) p. 372.

247. M. Ohtsuki, M.S. Isaacson and A.V. Crewe, Dark Field Imaging of Biological Macromolecules with the Scanning Transmission Electron Microscope, Proc. Nat'l Acad. Sci. (USA) 76 (1979) pp. 1228-32.

248. A.V. Crewe, Development of High Resolution STEM and Its Future, J. Electron Microscopy 28 (1979) pp. S9-S16.

249. A.V. Crewe, Direct Imaging of Atoms in Crystals and Molecules, Nobel Symposium (Stockholm, 1979). 
250. M. Utlaut, D. Hwang, M. Isaacson and $\mathbf{S}$. Solin, Electron Energy Loss Spectroscopy of Potassium Intercalated Graphite, Proc. 14th Biennial Conf. on Carbon (University Park, PA, 1979) p. 316.

251. M. Isaacson, M. Utlaut and $M$. Ohtsuki, Scanning Transmission Electron Microscopy of Very Thin Evaporated Carbon Films, Proc. 14th Biennial Conf. on Carbon (University Park, PA, 1979) pp. 103-04.

252. M. Isaacson, M. Utlaut and $M$. Ohtsuki, Direct Observation of the Diffusion of Heavy Atoms on the Surfact of Thin Amorphous Carbon Films, Proc. 14th Biennial Conf. on Carbon (University Park, PA, 1979) pp. 105-06.

253. M. Ohtsuki, M.S. Isaacson and A.V. Crewe, Preparation and Observation of Very Thin, Very Clean Substrates for Scanning Transmission Electron Microscopy, Scanning Electron Microscopy II (1979) pp. 375-82.

254. M. Isaacson, M. Ohtsuki and M. Utlaut (J. Hren, J.I. Goldstein and D.C. Joy, Eds.), "Electron Microscopy of Individual Atoms," Introduction to Analytical Electron Microscopy, New York: Plenum Publishing Co. (1979) pp. 343-368.
255. S.L. White, Images of Unstained Hemoglobin from the STEM, Proc. 37th Ann. EMSA Mtg. (1979) pp. 18-19.

256. M.S. Isaacson and M. Ohtsuki, Scanning Transmission Electron Microscopy and Electron Microdiffraction of Ferritin, Proc. 37th Ann. EMSA Mtg. (1979) pp. 20-21.

257. S.D. Golladay and M.K. Lamvik, Platinum Labeling of Methionine in Tropomyosin Paracrystals, Proc. 37th Ann. EMSA Mtg. (1979) pp. 26-27.

258. S. Usala, B. Brownstein, R. Haselkorn and H.O. Agrawal, Transcription Associated with Bacteriophage 06 Nucleocapsid, Proc. 37th Ann. EMSA Mtg. (1979) pp. 32-33.

259. M. Ohtsuki, Dark Field STEM Observation of Negatively Stained Tobacco Mosaic Virus (TMV): Effects of Radiation Damage, Proc. 37th Ann. EMSA Mtg. (1979) pp. 130-31.

260. M. Utlaut, M. Ohtsuki and M. Isaacson, Observations of the Diffusion of Heavy Atoms on Thin Amorphous Carbon Films, Proc. 37th Ann. EMSA Mtg. (1979) pp. 466-67.

261. M. Utlaut, Measurements of Single Atom Diffusion at Dif- 
ferent Temperatures, Proc. 37th Ann. EMSA Mtg. (1979) pp. 470-71.

262. M. Isaacson, M. Ohtsuki and M. Utlaut, Can We Determine the Structure of Thin Amorphous Films Using Scanning Transmission Electron Microscopy?, Proc. 37th Ann. EMSA Mtg. (1979) pp. 498-99.

263. M. Isaacson and M. Utlaut, On the Chemical Identificaion of Individual Atoms, Proc 37th Ann. EMSA Mtg. (1979) pp. 524-25.

264. M. Listvan, Thin Polycrystalline Graphite Films for High Resolution Microscopy, Proc. 37th Ann. EMSA Mtg. (1979) pp. 544-45.

265. M. Utlaut and M.S. Isaacson, A Comparison of Measured Single Atom Distributions with Random Distributions, Proc. 37th Ann. EMSA Mtg. (1979) pp. 546-47.

266. A.V. Crewe, Something Old, Something New for the STEM, Proc. 37th Ann. EMSA Mtg. (1979) pp. 560-63.

267. M.R. Sogard, Resolution in Electron Backscattering: A Monte Carlo Study, Proc. 37th Ann. EMSA Mtg. (1979) pp. 564-65.
268. M. Ohtsuki and M.S. Isaacson, Simple Test Specimens for Measuring Lattice Resolution and Probe Size of a STEM, Proc. 37th Ann. EMSA Mtg. (1979) pp. 568-69.

269. N.W. Parker, M. Utlaut and M.S. Isaacson, Design of Aberration-Corrected Magnetic Spectrometers, Proc. 37th Ann. EMSA Mtg. (1979) pp. 578-79.

270. N.W. Parker, M. Utlaut, M.S. Isaacson and A.V. Crewe, A New Analytical Electron Microscope, Proc. 37th Ann. EMSA Mtg. (1979) pp. 588-89.

271. R.P. Becker and M. Sogard, Visualization of Subsurface Structures in Cells and Tissues by Backscattered Electron Imaging, Scanning Electron Microscopy II (1979) pp. 835-870.

272. A.V. Crewe, Some Limitations on Electron Beam Lithography, J. Vac. Sci. Technol. 16 (1979) pp. 255-59.

273. M. Isaacson, Scanning Transmission Electron Microscopy at Near-Atomic Resolution: The Present State of the Art, Ultramicroscopy 4 (1979) p. 365.

274. A.V. Crewe, M.S. Isaacson and E. Zeitler (W. Hoppe and R. Mason, Eds.), "Progress in 
Scanning Transmission Electron Microscopy at the University of Chicago," Unconventional Electron Microscopy for Molecular Structure Determination, Braunschweig: Friedr. Vieweg \& Sohn (1979) pp. 23-48.

275. D.M. Hwang, M. Utlaut, M.S. Isaacson and S.A. Solin, Electron-Energy Loss Study of Stage-1 Potassium-Intercalated Graphite, Phys. Rev. Letters $\mathbf{4 3}$ (1979) pp. 882-86.

276. A.V. Crewe (Lerner and Trig, Eds.), "Electron Microscopy," Encyclopedia of Physics (1979-80).

\section{0}

277. A.V. Crewe (Lerner and Trig, Eds.), "Electron Microscopy," Encyclopedia of Physics (1979-80).

278. A.V. Crewe, Color Conversion in Electron Microscopy, Scanning 3 (1980) pp. 176-81.

279. A.V. Crewe, Imaging in Scanning Microscopes, Ultramicroscopy 5 (1980) pp. 131-38.

280. A.V. Crewe and D. A. Kopf, Limitations of Sextupole Correctors, Optik 56 (1980) pp. $391-99$.
281. M. Isaacson, M. Utlaut and D. Kopf (P.W. Hawkes, Ed.), "Computer Processing of Electron Microscope Images," Topics in Current Physics, New York: Springer-Verlag (1980).

282. M. Ohtsuki and A.V. Crewe, Optimal Imaging Techniques in the Scanning Transmission Electron Microscope: Applications to Biological Macromolecules, Proc. Nat'l Acad. Sci. (USA) 77 (1980) pp. 4051-54.

283. A.V. Crewe, The Physics of the High Resolution Scanning Microscope, Rep. Prog. Phys. 43 (1980) pp. 621-39.

284. D.M. Hwang, S.A. Solin, M. Utlaut and M.S. Isaacson, Electron Energy Loss Studies of Stage-2 Potassium Intercalated Graphite, Bull. of the APS 25 (1980) p. 336.

285. A.V. Crewe, The Sextupole as Corrector, Electron Microscopy I (1980) pp. 36-37.

286. A.V. Crewe and D. Kopf, A Sextupole System for the Correction of Spherical Aberration, Optik 55 (1980) pp. 1-10.

287. A.V. Crewe and D. Kopf, The Use of Non-optimal Apertures in the STEM, Optik 55 (1980) pp. 325-27. 
288. M.R. Sogard, Backscattered Electron Energy Spectra for Thin Films from an Extension of the Everhart Theory, J. Appl. Phys. 51 (1980) pp. 4412-16.

289. M.R. Sogard, An Empirical Study of Electron Backscattering from Thin Films, J. Appl. Phys. 51 (1980) pp. 4417-25.

290. D.M. Hwang, M. Utlaut, M.S. Isaacson and S.A. Solin, Dielectric Functions of Stage One Potassium Intercalated Graphite Single Crystals Determined by Electron Microscopy, Physica 99B (1980) pp. 435-40.

291. A.V. Crewe and M. Ohtsuki, The Use of Optimal Scanning in the STEM, 7th European Congress on Electron Microscopy (Netherlands, 1980).

292. A.V. Crewe, P. Lin and J. Schuler, 1 MeV STEM: A Progress Report, Proc. 38th Ann. EMSA Mtg. (1980) pp. 6-7.

293. A.V. Crewe, D. Kopf, M. Ohtsuki and P. Usala, Further Uses of Color in Scanning Transmission Electron Microscopy, Proc 38th Ann. EMSA Mtg. (1980).

294. E.M. Kirkland, W.T. Freeman, M. Ohtsuki and B.M. Siegel,
Digital Image Processing of STEM Images of Tobacco Mosaic Virus (TMV), Proc. 38th Ann. EMSA Mtg. (1980) pp. 40-41.

295. M. Listvan, A.V. Crewe and W. Mankawich, A Temperature-Controlled High Resolution Stage, Proc. 38th Ann. EMSA Mtg. (1980) pp. 58-59.

296. A.V. Crewe, Theory of Optimal Scanning in the STEM, Proc. 38th Ann. EMSA Mtg. (1980) pp. 60-61.

297. M. Ohtsuki and A.V. Crewe, Application of the STEM Optimum Imaging Method on a Biological Macromolecule, Proc. 38th Ann. EMSA Mtg. (1980) pp. 62-63.

298. A.V. Crewe, A New Possibility for Correcting $C_{s}$, Proc. 38th Ann. EMSA Mtg. (1980) pp. 274-76.

299. A.V. Crewe, R.K. Mittleman and R.L. Rosman, Preparation of Thin Graphite Supporting Films, Proc. 38th Ann. EMSA Mtg. (1980) pp. 410-11.

300. O.H. Kapp, M. Ohtsuki and S.N. Vinogradov, Structural Investigation of Invertebrate $\mathrm{He}$ moglobins Using the STEM, 
Proc. 38th Ann. EMSA Mtg. (1980) pp. 676-77.

301. M. Utlaut, Direct Observation of the Behavior of Heavy Single Atoms on Amorphous Carbon Substrates, Phys. Rev. B 22 (1980) pp. 4650-60.

302. A.V. Crewe, Studies on Sextupole Correctors, Optik 57 (1980) pp. 313.27.

303. M. Isaacson and M. Ohtsuki, Scanning Transmission Electron Microscopy of Small Inhomogeneous Particles: Applications to Ferritin, Scanning Electron Microscopy I (1980) pp. $73-80$.

304. M. Ohtsuki, Observation of Unstained Biological Macromolecules with the STEM, Ultramicroscopy 5 (1980) pp. 317-23.

305. M. Ohtsuki, Test Specimens for a Dark Field STEM Imaging: Measuring Lattice Spacing and Electron Probe Size of a STEM and Testing Visibility of Atoms of Various Atomic Numbers, Ultramicroscopy 5 (1980) pp. $325-32$.

1981

306. A.V. Crewe and M. Ohtsuki, Optimal Scanning and Image Processing with the STEM,
Uliramicroscopy 7 (1981) pp. 13-18.

307. O.H. Kapp, M. Ohtsuki, S.N. Vinogradov, Oxygen Binding Study and High Resolution Scanning Transmission Electron Microscopy (STEM) of Alkaline Dissociation Products of Lumbricus terrestris Hemoglobin, Proc. 7th Int'l Biophysics Congress and 3rd Pan-American Biochemistry Congress (Mexico City, Mexico, 1981) p. 60.

308. E.J. Kirkland, W.T. Freeman, M. Ohtsuki, M.S. Isaacson and B.M. Siegal, Computer Image Processing of STEM Images of Tobacco Mosaic Virus, Ultramicroscopy 6 (1981) pp. 367-76.

309. D.A. Kopf, Measurement of the Intensity Distribution in a STEM Probe, Optik 59 (1981) pp. 89-110.

310. M. Ohtsuki, Preparation, Observation, and Imaging Methods for High Resolution Scanning Transmission Electron Microscopy of a Biological Specimen, Waseda University (Tokyo, Japan, 1981).

311. J. Snipes, M. Ohtsuki, S.N. Vinogradov and A.V. Crewe, Nucleation of Indium Atoms on an Amorphous Carbon Sub- 
strate, Proc. 39th Ann. EMSA

Mtg. (1981) pp. 220-21.

312. O.H. Kapp, M. Ohtsuki, S.N. Vinogradov and A.V. Crewe, Scanning Transmission Electron Microscopy (STEM) of Annelid Extracellular Hemoglobins, Proc. 39th Ann. EMSA Mtg. (1981) pp. 432-33.

313. A.V. Crewe and M. Ohtsuki, Digital Processing of STEM Images, Proc. 39th Ann. EMSA Mtg. (1981).

314. O.H. Kapp, M. Ohtsuki, N. Robin, S.N. Vinogradov and A.V. Crewe, Alkaline Dissociation Products of Lumbricus terrestris Hemoglobin Viewed with the STEM, Proc. 39tin Ann. EMSA Mtg. (1981) pp. 434-35.

315. N.W. Parker, M. Utlaut and A.V. Crewe, Results from a New Analytical Electron Microscope, Proc. 39th Ann. EMSA Mtg. (1981) pp. 378-79.

316. E.J. Kirkland, W.T. Freeman, M. Ohtsuki, M.S. Isaacson and B.M. Siegel, Digital Image Processing of STEM Images of Tobacco Mosaic Virus, Proc. 39th Ann. EMSA Mtg. (1981).

317. D.M. Hwang, M. Utlaut and S.A. Solin, Electron Energy Loss Studies of Potassium
Intercalated Graphite, Synthetic Metals 3 (1981) pp. $81-88$.

318. S.N. Vinogradov, O.H. Kapp and M. Ohtsuki (J.R. Harris, Ed.), "The Extracellular Hemoglobins and Chlorocruorins of Annelids", Electron Microscopy of Protcins, Vol. 3, London: Academic Press Inc. (1981) pp. 135-164.

1982

319. A.V. Crewe, A System for the Correction of Axial Aperture Aberrations in Electron Lenses, Optik 60 (1982) pp. 271-81.

320. A.V. Crewe and M. Ohtsuki, A Digital Processor for Use with STEM Images, Proc. 10th Int'l Congress on Electron Microscopy (Hamburg, West Germany, 1982) pp. 531-32.

321. M. Ohtsuki and A.V. Crewe, A Thirteenth Subunit Revealed in Lumbricus terrestris Hemoglobin in STEM Low Dose Images, Proc. 10th Int'l Congress on Electron Microscopy (Hamburg, West Germany, 1982) pp. 493-94.

322. A.V. Crewe and M. Ohtsuki, A "Stand Alone" Image Processing System for STEM Images, Ultramicroscopy 9 (1982) pp. 101-08. 
323. A.V. Crewe and F. Scaduto, A Gradient Field Spectrometer for STEM Use, Proc. 40th Ann. EMSA Mtg. (1982).

324. M. Ohtsuki and A.V. Crewe, Observation of a Central Subunit in Annelid Extracellular Hemoglobin Using the STEM Digital Processing Techniques, Proc. 40th Ann. EMSA Mtg. (1982) pp. 704-05.

325. A.V. Crewe and D. Salzman, On the Optimum Resolution for a Corrected STEM, Ultramicroscopy 9 (1982) pp. 373-78.

326. A.V. Crewe and M. Ohtsuki, Digital Processing of STEM Images and False Color Displays, Hitachi Instrument News 11 (1982) pp. 2-5.

327. O.H. Kapp, S.N. Vinogradov, M. Ohtsuki and A.V. Crewe, Scanning Transmission Electron Microscopy of Extracellular Annelid Hemoglobins, Biochimica et Biophysica Acta 704 (1982) pp. 546-548.

328. S.D. Golladay, Tropomyosin Structure and Intermolecular Contacts in $\mathrm{Mg}$ Paracrystals (Ph.D. Thesis), Biochimica et Biophysica Acta 705 (1982) pp. 277-83.
329. A.V. Crewe, A Low Cost Image Analysis System for Scanning Transmission Electron Microscopy Low-Dose Images, Scanning Electron Microscopy IV (1982) pp. 1597-1601.

\section{3}

330. E.G. Chen, M. Ohtsuki and A.V. Crewe, Attractive and Repulsive Forces Between Clusters: A STEM Study of Platinum Clusters, Proc. 4lst Ann. EMSA Mtg. (1983) pp. 334-35.

331. M. Ohtsuki, J.J. Schuler, A.V. Crewe and $T$. Ichinokawa, Specimen Heating Stage with In situ Evaporator in UHV-STEM for the Observation and Characterization of Monolayered Superstructures, Proc. 41st Ann. EMSA Mtg. (1983) pp. 308-09.

332. M.A. Listvan, The Development of Order in a System of Metal Clusters, Proc. 41st Ann. EMSA Mtg. (1983) pp. 336-37.

333. M.A. Listvan and R.P. Andres, Production and STEM Examination of Controlled-Size Clusters, Proc. 4lst Ann. EMSA Mig. (1983) pp. 338-39.

334. O.H. Kapp, M. Ohtsuki, A.V. Crewe and S.N. Vinogradov, Observation of Reconstituted Lumbricus terrestris Hemoglobin with the STEM, Proc. $41 s t$ 
Ann. EMSA Mtg. (1983) pp. 594-55.

335. S.N. Vinogradov, G. Polidori, J. Van Gelderen and O.H. Kapp, The Dissociation of the Extracellular Hemoglobin of Nephtys incisa, Comp. Biochem. Physiol. 76B (1983) pp. 207-14.

336. M.A. Listvan, Direct Observations of Small Gold Clusters and In Situ Cluster Growth by STEM, J. Mol. Catalysis 20 (1983) pp. 265-278.

337. S.N. Vinogradov and O.H. Kapp (C.H.W. Hirs and S. Timasheff, Eds.), "Removal of Sodium Dodecyl Sulfate from Proteins by Ion Retardation Chromatography", Part $J$ of Methods in Enzymology New York: Academic Press (1983) pp. 259-63.

338. S.N. Vinogradov and O.H. Kapp, Dissociation and Reassociation of Earthworm Hemoglobin, Life Chemistry Reports Suppl. 1 (1983) pp. 147-156.

339. S.N. Vinogradov, O.H. Kapp, U. Messerschmidt, E. Schwartz and 1. Pilz, Nephtys: An Unusual Extracelleular Annelid Hemoglobin with a Central Subunit, Life Chemistry Reports Suppl.1 (1983) pp. 197-202.
340. A.V. Crewe, High Resolution Scanning Transmission Electron Microscopy, Science 221 (1983) pp. 325-30.

341. D.M. Hwang, N.W. Parker, M. Utlaut and A.V. Crewe, Observation of Non-hexagonal Superlattices in High-stage Cesium Intercalated Graphite, Phys. Rev. B 27 (1983) pp. 1458-61.

342. M. Ohtsuki, A High Resolution STEM and its Application to the Observation of Biological Macromolecules, J. Cryst. Soc. Japan 25 (1983) pp. 38-50.

343. M. Ohtsuki and A.V. Crewe, Direct Observation of Biological Macromolecules with the Atomic Resolution Scanning Transmission Electron Microscope, Phys. Soc. of Japan 38 (1983) pp. 550-56.

344. E.M. Kritchman, Ideal Second Stages in Tandem with Spherical Mirrors, Solar Energy 30 (1983) pp. 481-82.

345. A.V. Crewe and M. Ohtsuki, Evidence for a Central Substructure in a Lumbricus terrestris Hemoglobin Obtained with STEM Low-dose and Digital Processing Techniques, $J$. Ultrastructure Research $\mathbf{8 3}$ (1983) pp. 312-18. 


\section{4}

346. A.V. Crewe and D.A. Crewe, Inexact Reconstructions from Projections, Ultramicroscopy 12 (1984) pp. 293-98.

347. A.V. Crewe, D.A. Crewe and O.H. Kapp, Inexact Three Dimensional Reconstruction of a Biological Macromolecule from a Restricted Number of Projections, Ultramicroscopy 13 (1984) pp. 365-72.

348. O.H. Kapp, G. Polidori, M. Mainwaring, A.V. Crewe and S.N. Vinogradov, The Reassociation of Lumbricus terrestris Hemoglobin Dissociated at Alkaline $\mathrm{pH}, J$. Biol. Chem. 259 (1984) pp. 628-39.

349. O.H. Kapp and A.V. Crewe, The Size and Shape of the Extracellular Hemoglobin of Tubifex tubifex, Biochimica et Biophys. Acta 789 (1984) pp. 294-301.

350. E.G. Chen, M. Ohtsuki and A.V. Crewe, A STEM Study of a Platinum Deposit on an Amorphous Carbon Film: The Effects of Contact Voltage in the Nucleation Process, Surf. Sci. 144 (1984) pp. 465-76.

351. R.S. Lewis and M. Ohtsuki, Interstellar Carbon Grains from the Murchison Meteorite: Electron Microscopy, Proc. 47th Annual Meteoretical Soc. Meeting (Albuquerque, NM, 1984) pp. L-8.

352. M. Ohtsuki, C. Edelstein and A.M. Scanu, Similarity in Structures of Canine High Density Lipoproteins Containing Either Apo A-I or Human Apo A-II as Assessed by a Scanning Transmission Electron Micrsocpy Digital Techniques, Arteriosclerosis 4 (1984) p. 566a.

353. A.V. Crewe, Optimisation of a STEM, Proc. Roy. Microsc. Soc. MICRO 8419 (1984) p. S59.

354. A.V. Crewe, Very High Resolution: A Place for the STEM, Proc. 42nd Ann. EMSA Mtg. (1984) pp. 372-75.

355. A.V. Crewe and D.A. Crewe, Inexact Reconstruction: $A$. The Basic Method, Proc. 42nd Ann. EMSA Mtg. (1984) pp. 634-35.

356. O.H. Kapp, D.A. Crewe and A.V. Crewe, Inexact Reconstruction: B. Application to a Biological Object, Proc. 42nd Ann. EMSA Mtg. (1984) pp. 636-37.

357. A.V. Crewe, D.A. Crewe and O.H. Kapp, Three Dimensional 
Reconstruction of Lumbricus terrestris Hemoglobin from a Restricted Number of STEM Projections, Biophysical Journal 45 (1984) p. 371A.

358. D.A. Crewe, A.V. Crewe and O.H. Kapp, Inexact Three Dimensional Reconstruction of Lumbricus terrestris Hemoglobin, Proc. ASBC/AII Meeting (St. Louis, 1984) p. 1562.

359. C. Schwartz, S.N. Vinogradov, O.H. Kapp, A.V. Crewe and M. Mainwaring, Molecular Size and Subunits of Myxicola chlorocruorin, Proc. ASBC/AII Meeting (St. Louis, 1984) p. 1562.

360. O.H. Kapp, A.V. Crewe, M.G. Mainwaring, C. Schwartz and S.N. Vinogradov, The Size and Shape of the Hemoglobin of Macrobdella decora, Proc. ASBC/AII Meeting (St. Louis, 1984) p. 1578.

361. M.G. Mainwaring, S.N. Vinogradov, O.H. Kapp and A.V. Crewe, Acid Dissociation and Reassociation of Lumbricus terrestris Hemoglobin, Proc. $A S B C / A I I$ Meeting (St. Louis, 1984) p. 1579.

362. S.N. Vinogradov, O.H. Kapp, A.V. Crewe and $M$. Mainwaring, Studies of the Extracellular Hemoglobin of
Amphitrita ornata, Proc. ASBC/AII Meeting (St. Louis, 1984) p. 1579.

363. S.N. Vinogradov, J.A. Van Gelderin, G. Polidori and O.H. Kapp, Dissociation of the Extracellular Hemoglobin of Nephytys, Comp. Biochem. Physiol. 76B (1984) pp. 207-214.

364. O.H. Kapp, A.V. Crewe, M.G. Mainwaring and S.N. Vinogradov, The Size and Shape of the Hemoglobin of Macrobdella decora, Proc. 8th Inti. Biophys. Congr. (Bristol, England, 1984) p. 234.

365. G.R. McNamara, O.H. Kapp, T.A. Barrett, P.E. Mooney, X. Jiye and A.V. Crewe, A New Image Processing System for STEM Images, Proc. 8th Intl. Biophys. Congr. (Bristol, England, 1984) p. 234.

366. A.V. Crewe, An Introduction to the STEM, J. Ultrastr. Res. 88 (1984) pp. 94-104.

367. A.V. Crewe, The Sextupole Corrector 1. Algebraic Calculations, Optik 69 (1984) pp. 24-29.

368. M. Ohtsuki, An Introduction to the $2.5 \AA$ STEM, Enrico Fermi Institute (The University of Chicago, 1984). 
369. M. Ohtsuki and E. Schudy, Assessment of Morphology of Assymmetrical Biological Macromolecules with Digital Techniques, J. Ultrast. Res. 89 (1984) pp. 303-08.

370. O.H. Kapp and A.V. Crewe, Comparison of the Molecular Size and Shape of the Extracellular Hemoglobins of Tubifex tubifex and Lumbricus terrestris, Biochim. et Biophys. Acta 789 (1984) pp. 294-301.

\section{5}

371. A.V. Crewe and D.A. Crewe, Inexact Reconstruction: Some Improvements, Ultramicroscopy 16 (1985) pp. 33-40.

372. A.V. Crewe and X. Jiye, Correction of Spherical and Coma Aberrations with a SextupoleRound Lens-Sextupoie System, Optik 69 (1985) pp. 141-46.

373. X. Jiye, Z. Shao and A.V. Crewe, The Wave Electron Optical Properties of a Magnetic Round Lens Corrected with Sextupoles, Optik 70 (1985) pp. 37-42.

374. Z. Shao and X. Jiye, Two Dimensional Phase Retrieval from Image and Diffraction Patterns in Electron Microscopes, Optik 71 (1985) pp. 15-22.
375. X. Jiye and Z. Shao, Three Dimensional Algebraic Reconstruction from Three Mutually Orthogonal Projections, Optik 71 (1985) pp. 143-48.

376. A.V. Crewe, Towards the Ultimate Scanning Microscope, Scanning Electron Microscopy II (1985) pp. 467-72.

377. S.N. Vinogradov, P.R. Standley, M.G. Mainwaring, O.H. Kapp and A.V. Crewe, The Molecular Size of Myxicola infundibulum chlorocruorin and its Subunits, Biochimica et Biophysica Acta 828 (1985) pp. 43-50.

378. X. Jiye and O.H. Kapp, Classification of Projection Images by Multivariate Matrix Analysis, Proc. FASEB Mtg. (Anaheim, CA, 1985) p. 1096.

379. O.H. Kapp and X. Jiye, Three Dimensional Reconstruction of a Biological Object Using Multivariate Matrix Analysis, Proc. FASEB Mtg. (Anaheim, CA, 1985) p. 1096.

380. O.H. Kapp, D.A. Crewe, A.V. Crewe, M.G. Mainwaring and S.N. Vinogradov, Three Dimensional Reconstruction of the Hemoglobin of Lumbricus terrestris from STEM Projections, 13th Int'l Congress of Biochemistry (Amsterdam, 1985). 
381. G.R. McNamara, O.H. Kapp and A.V. Crewe, A New Image Processing System for STEM Images, Proc. 13th Int'l Congress of Biochemistry (Amsterdam, The Netherlands, 1985).

382. X. Jiye and O.H. Kapp, Classification of Projection Images by Multivariate Matrix Analysis, Optik 70 (1985) pp. 101-08.

383. O.H. Kapp and X. Jiye, Classification of Electron Microscopic Images by Multivariate Matrix Analysis, Optik $\mathbf{7 0}$ (1985) pp. 146-151.

384. X. Jiye and Z. Shao, A Study of an Inhomogeneous Gradient Magnetic Field Spectrometer with a Curvilinear Axis, Optik 71 (1985) pp. 73-79.

385. D. Salzman, M. O'Connor, R. Smith, A. Goodman and D. Breslau, A Unified Environment for Image Processing, Graphics, and Instrument Control, Proc. Ist Int'l Conf. on Computer Workstations (San Jose, 1985) pp. 173-80.

386. J. Lamy, P.Y. Sizaret, T. Musmeci, O.H. Kapp and S.N. Vinogradov, Has Annelid Erythrocruorin a 6-fold Axis of Symmetry?, Int'l Symposium on Invertebrate Oxygen Carriers (Tutzing, West Germany, 1985).
387. O.H. Kapp, Capabilities of the STEM: Present and Future, Frontiers in Science Symposium, 190th American Chemical Society (Chicago, 1985).

388. R. Levi-Setti, G. Crow, Y.L. Wang, N.W. Parker and R.K. Mittleman, High-Resolution Scanning-Ion-Microprobe Study of Graphite and its Intercalation Compounds, Phys. Rev. Let. 54 (1985) pp. 2615-18.

389. A.V. Crewe, Gravure in the Digital Age, Gravure Technical Assoc. Convention (Chicago, 1985).

390. A.V. Crewe, The Chicago Microscope Project, IBM-ACIS Conf. (Santa Clara, 1985).

391. G. Crow, Y.L. Wang, N.W. Parker, R. Mittleman, X.W. Qian and S.A. Solin, Applications of Microscopic Probes in the Study of Graphite Intercalation Compounds, Synthetic Metals (1985).

1986

392. X. Jiye and O.H. Kapp, Three Dimensional Algebraic Reconstruction from Projections of Multiple Grey Level Objects, Optik 72 (1986) pp. 87-94. 
393. O.H. Kapp and X. Jiye, Eigenvalue Analysis for Classifying Projection Images of an Object with Arbitrary Orientation, Optik 73 (1986) pp. 51-55.

394. X. Jiye and O.H. Kapp, Eigenvalue and Eigenvector Analysis in Multivariate Matrix Theory for Classifying Projection Images, Optik 72 (1986) pp. 143-48.

395. O.H. Kapp, The High Resolution STEM, Now and Later, NAS Conference on Recent Advances in Electron and Light Imaging in Biology and Medicine (New York, 1986).

396. X. Jiye and O.H. Kapp, Supplement to Three Dimensional Algebraic Reconstruction from Projections of Multiple Grey Level Objects, Optik 73 (1986) pp. 10-12.

397. X. Jiye, Advances in Electronics and Electron Physius, in Academic Press, Suppl. 17 (1986).

398. A.V. Crewe, Limits of the STEM, Proc. 44th Ann. EMSA Mtg. (1986) pp. 764-65.

399. C. Mu and W. Wolbach, Particulate Carbon at the Cretaceous-Tertiary Boundary, Proc. 44th Ann. EMSA Mtg. (1986) pp. 782-83.
400. C. Mu and Z. Shao, Inexact Reconstruction with Added Noise, Proc. 44th Ann. EMSA Mtg. (1986) pp. 184-85.

401. R.K. Mittleman and N.W. Parker, SbCl5 Intercalated Graphite, Proc. 44th Ann. EMSA Mtg. (1986) pp. 780-81.

402. R.K. Mittleman and N.W. Parker, Micrograph Image Processing System, Proc. 44th Ann. EMSA Mtg. (1986) pp. 872-73.

403. T. Barrett, Reconstruction with Noisy Data, Proc. 44th Ann. EMSA Mtg. (1986) pp. 186-87.

404. M.G. Mainwaring, S.D. Lugo, R.A. Fingol, O.H. Kapp, S.N. Vinogradov, The Dissociation of the Extracellular Hemoglobin of Lumbricus terrestris at Acid $\mathrm{pH}$ and its Reassociation at Neutral pH, J. Biol. Chem. 261 (1986) pp. 10899-1090.

405. A.V. Crewe, What to Teach About the Physics of the SEM, $S E M$ Mtg. (New Orleans, 1986).

406. A.V. Crewe, Thoughts on Images and Objects, Institute for Imaging Science (Univ. of Chicago, 1986).

407. A.V. Crewe, High Resolution Scanning Transmission Electron Microscopy, Frontiers of 
Electron Microscopy in Materials Science (Argonne National Laboratory, 1986).

408. A.V. Crewe, Is There a Limit to the Resolving Power of the SEM?, Proc. XIth Int'l Congress on Electron Microscopy III (Kyoto, 1986) pp. 2105-2108.

409. A.V. Crewe, A Totally New Computer-Controlled High Resolution SEM, 5th Ann. Symposium on Adv. in Electron Microscopy (Beaufort, N.C., 1986).

410. A.V. Crewe, Scanning Electron Microscopy at the Atomic Level, Proc. Ist Int'l New Materials Conf. and Exhibition 1 (Osaka, 1986) pp. 43-45.

411. S.N. Vinogradov, S.D. Lugo, M.G. Mainwaring, O.H. Kapp and A.V. Crewe, Bracelet Protein: A Quaternary Structure Proposed for the Giant Extracellular Hemoglobin of Lumbricus terrestris, Proc. Nat'l Acad. Sci. Sciences (USA) 83 (1986) pp. 8034-8038.

412. M. Listvan, Determination of Time Dependence of Domain Growth by Direct Observation of Small Metal Clusters, Surf. Sci. 173 (1986) pp. 294-309.

413. S. Lugo, O.H. Kapp, M. Mainwaring and S.N. Vinogradov, The Dissociation of the Extracellular Hemoglobin of Lumbricus terrestris at Acid $\mathrm{pH}$ and its Reassociation at Neutral pH, 30th Ann. Mtg. Biophysical Society; Biophysical Journal 49 (San Francisco, 1985) p. $543 \mathrm{a}$.

414. S.N. Vinogradov, S. Lugo, M. Mainwaring and O.H. Kapp, Bracelet Protein: A New Model of the Quaternary Structure of Lumbricus terrestris Hemoglobin, 30th Ann. Mtg. Biophysical Society; Biophysical Journal 49 (San Francisco, 1985) p. 543a.

415. S. Lugo, O.H. Kapp, M. Mainwaring and S.N. Vinogradov, The Dissociation of the Extracellular Hemoglobin of Lumbricus terrestris at Neutral $\mathrm{pH}$, 30th Ann. Mtg. Biophysical Society; Biophysical Journal 49 (San Francisco, 1985) p. 543a.

1987

416. N.W. Parker, R.K. Mittleman and A.V. Crewe, New Scanning Transmission Electron Microscope Microanalytical System, Rev. Scientific Instruments $\mathbf{5 8}$ (1987) pp. 174-182.

417. Z. Shao, Probe Size and 5thOrder Aberration, 45th Ann. EMSA Mtg. (1987) pp. 134-35. 
418. Z. Shao and A.V. Crewe, Chromatic Aberration and LowVoltage SEM, Proc. 45th Ann. EMSA Mtg. (1987) pp. 546-47.

419. Z. Shao and A.V. Crewe, Spherical Aberrations of Multipoles, J. Appl. Physics 62 (1987) pp. 1149-53.

420. Z. Shao, A Study on Multipole Systems as Correctors, Optik 75 (1987) pp. 152-57.

421. Z. Shao, C. Mu and O.H. Kapp, Inexact Reconstruction of Multiple Grey Level Objects from their Projections, Optik $\mathbf{7 6}$ (1987) pp. 12-17.

422. A.V. Crewe, Optimisation of Small Electron Probes, Ultramicroscopy 23 (1987) pp. 159-168.

423. Z. Shao and A.V. Crewe, Chromatic Aberration Effects in Small Electron Probes, Ultramicroscopy 23 (1987) pp. 169-174.

424. R.K. Mittleman, N.W. Parker and A.V. Crewe, Electron Diffraction Study of $\mathrm{SbCl}_{5}$ Intercalated Graphite, Phys. Rev. B 36 (1987) pp. 7590-7600.

425. V.D. Beck, A Wave Optical Treatment of Space Charge, Optik 76 (1987) pp. 167-69.
426. O.H. Kapp, M.G. Mainwaring, S.N. Vinogradov and A.V. Crewe, A Scanning Transmission Electron Microscopic Examination of the Hexagonal Bilayer Structures Formed by the Reassociation of Three Out of the Four Subunits of the Extracellular Hemoglobin of Lumbricus terrestris, Proc. FASEB Mtg. 46 (Philadelphia, 1987) p. 2266.

427. O.H. Kapp, M.G. Mainwaring and S.N. Vinogradov and A.V. Crewe, A Scanning Transmission Electron Microscopic Examination of the Hexagonal Bilayer Structures Formed by the Reassociation of Three Out of the Four Subunits of the Extracellular Hemoglobin of Lumbricus terresris, Proc. Nat'l Acad. of Sciences (USA) 84 (1987) pp. 7532-36.

428. R.K. Mittleman, Electron Diffraction Study of RubidiumIntercalated Graphite Through the Deintercalation Process, Phys. Rev. B 36 (1987) pp. 6001-6011.

1988

429. C. Mu, Z. Shao and O.H. Kapp, Three Dimensional Reconstruction from Noisy Projections, Optik 79 (1988) p. 99. 
430. Z. Shao and A.V. Crewe, A Study on the Optimisation of Apertures in an Aberrated Probe Forming System, Optik 79 (1988) pp. 105-110.

431. Z. Shao, V.D. Beck and A.V. Crewe, A Study of Octupoles as Correctors, J. Applied Phys. 64 (1988) pp. 1646-1651.

432. Z. Shao and A.V. Crewe, Ideal Lenses and the Scherzer Theorem: A Supplement, Ultramicroscopy 26 (1988) p. 385.

433. Z. Shao, Toward HighResolution Low-Voltage SEM, Proc. 46th Ann. EMSA Mtg. (1988) pp. 218-19.

434. A.V. Crewe, Instrumentation for a Corrected STEM, Proc. 46th Ann. EMSA Mtg. (1988) pp. 652-53.

435. A.V. Crewe, Some Notes on the History of the STEM, Proc. 46th Ann. EMSA Mtg. (1988) pp. 234-35.

436. P.E. Mooney, A Compact, Digital, Optically Isolated Control and Support System for a Field Emission Source on the $200 \mathrm{Kv}$ STEM, Proc. 46th Ann. EMSA Mtg. (1988) pp. 654-55.

437. Z. Shao, Correction of Spherical Aberrations in the Transmission
Eiectron Microscope, Optik $\mathbf{8 0}$ (1988) pp. 61-75.

438. Z. Shao, New Lens for a Low Voltage SEM, Rev. Scientific Instruments 59 (1988) p. 1985.

439. Z. Shao, On the 5th Order Aberration in a Sextupole Corrected System, Rev. Scientific Instruments $59 \quad$ (1988) pp. 2429-2437.

440. O.H. Kapp, J.S. Wall and S.N. Vinogradov, Quaternary Structure and Molecular Weight of the Giant Extracellular Hemoglobins, Asilomar Conference on Oxygen Binding Heme Proteins (Pacific Grove, CA, 1988).

441. S.N. Vinogradov and O.H. Kapp, Determination of the Stochiometry of Multi-subunit Proteins, Asilomar Conference on Oxygen Binding Heme Proteins (Pacific Grove, CA, 1988).

442. O.H. Kapp, J.S. Wall and S.N. Vinogradov, Bracelet Structures Obtained From Invertebrate Hemoglobins, Proc. Protein Society (San Diego, CA, 1988).

443. T. Suzuki, O.H. Kapp and T. Gotoh, Novel S-S Loops in the Giant Hemoglobin of Tylorrhynchus heterochaetus, $J$. Biol. Chem. 263 (1988) pp. 18524-1852. 
444. C. Mu, Z. Shao and O.H. Kapp, Three Dimensional Reconstruction from Noisy Projections, Optik. 79 (1988) p. 99.

445. O.H. Kapp, J.S. Wall, M.G. Mainwaring and S.N. Vinogradov, The Molecular Dimensions and Masses of Annelid Extracellular Hemoglobins and Chlorocruorins, 32nd Ann. Mtg. Biophys. Soc. (Arizona, 1988).

446. S.N. Vinogradov, MG. Mainwaring and O.H. Kapp, The Structure of the Annelid Extracellular Hemoglobins, 32nd Ann. Mtg. Biophys. Soc. (Arizona, 1988).

447. Z. Shao and A.V. Crewe, A Study on the Optimisation of Apertures in an Aberrated Probe Forming System, Optik 79 (1988) pp. 105-110.

448. Z. Shao, V.D. Beck and A.V. Crewe, A Study of Octupoles as Correctors, J. Applied Phys. 64 (1988) pp. 1646-165i.

449. Z. Shao and A.V. Crewe, Ideal Lenses and the Scherzer Theorem: A Supplement, Ultramicroscopy 26 (1988) p. 385.

450. Z. Shao, Toward HighResolution Low-Voltage SEM,
Proc. 46th Ann. EMSA Mtg. (1988) pp. 218-19.

451. A.V. Crewe, Instrumentation for a Corrected STEM, Proc. 46th Ann. EMSA Mtg. (1988) pp. 652-53.

452. A.V. Crewe, Some Notes on the History of the STEM, Proc. 46th Ann. EMSA Mtg. (1988) pp. 234-35.

453. P.E. Mooney, A Compact, Digital, Optically Isolated Control and Support System for a Field Emission Source on the $200 \mathrm{Kv}$ STEM, Proc. 46th Ann. EMSA Mtg. (1988) pp. 654-55.

454. Z. Shao, Correction of Spherical Aberrations in the Transmission Electron Microscope, Optik 80 (1988) pp. 61-75.

455. Z. Shao, New Lens for a Low Voltage SEM, Rev. Scientific Instruments 59 (1988) p. 1985.

456. Z. Shao, On the 5th Order Aberration in a Sextupole Corrected System, Rev. Scientific Instruments $59 \quad$ (1988) pp. 2429-2437.

457. O.H. Kapp, J.S. Wall and S.N. Vinogradov, Quaternary Structure and Molecular Weight of the Giant Extracellular Hemoglobins, Asilomar Conference on 
Oxygen Binding Heme Proteins (Pacific Grove, CA, 1988).

458. S.N. Vinogradov and O.H. Kapp, Determination of the Stoechiometry of Multi-subunit Proteins, Asilomar Conference on Oxygen Binding Heme Proteins (Pacific Grove, CA, 1988).

459. O.H. Kapp, J.S. Wall and S.N. Vinogradov, Bracelet Structures Obtained From Invertebrate Hemoglobins, Proc. Protein Society (San Diego, CA, 1988).

\section{9}

460. Z. Shao, Extraction of Secondary Electrons in a Newly Proposed Immersion Lens, Rev. Scientific Instruments 60 (1989) pp. 693-699.

461. A.V. Crewe, D.L. Clayton, D.A. Crewe, and K. Moscicka, User-Friendly Field Emission, Proc. 47th Annual EMSA Mtg. (San Antonio, TX, 1989).

462. A.V. Crewe, Small, Cool Lenses, Proc. 47th Annual EMSA Mtg. (San Aritonio, TX, 1989).

463. O.H. Kapp and S.N. Vinogradov, Direct Calculation of Subunit Stoichiometry from Amino Acid Compositions of Multimeric Proteins and Their Subunits, International Sympo- sium on Invertebrate Dioxygen Carriers (Leuven, Belgium, 1989).

464. O.H. Kapp, J.S. Wall and S.N. Vinogradov, Comparison of the Threc-Dimensional Reconstructions of the Hemoglobins of Lumbricus terrestris and Macrobdella decora from STEM data, International Symposium on Invertebrate Dioxygen Carriers (Leuven, Belgium, 1989).

465. O.H. Kapp, M. Schmuck, I. Pilz and S.N. Vinogradov, Comparison of the Molecular Dimensions and Hydrodynamic Properties of Annelid Hemoglobins Obtained by ST'EM and SAXS, International Symposium on Invertebrate Dioxygen Carriers (Leuven, Belgium, 1989).

466. O.H. Kapp and S.N. Vinogradov, Direct Calculation of Subunit Stoichiometry from Amino Acid Compositions of Multimeric Proteins and Their Subunits, Invertebrate Dioxygen Carriers (1989). University of Leuven press, pp. 213-217.

467. O.H. Kapp, J.S. Wall and S.N. Vinogradov, Comparison of the Three-Dimensional Reconstructions of the Hemoglobins of Lumbricus terrestris and Macrobdella decora from STEM data, Invertebrate 
Dioxygen Carriers (1989). University of Leuven press, pp. 229-233.

468. O.H. Kapp, M. Schmuck, I. Pilz and S.N. Vinogradov, Comparison of the Molecular Dimensions and Hydrodynamic Properties of Annelid Hemoglobins Obtained by STEM and SAXS, Invertebrate Dioxygen Carriers (1989). University of Leuven press, pp. 219-223.

469. Z. Shao and P.S.D. Lin, A High Resolution Low Voltage Electron Optical System For Very Large Specimens, Rev. Sci. Instrum. 60 (1989) p. 3434.

470. Z. Shao and X. D. Wu, Appl. Phys. Lett. 55 (1989) p. 2696.

1990

471. A.V. Crewe, Some thoughts on ultra-high Resolution, Int. Symp. elec. Micro., Beijing, China (1990) p. 1. World Scientifc

472. A.V. Crewe, Beyond One Angstrom, Proceedings of the XIIth International Congress for Electron Microscopy (1990).

473. O.H. Kapp, A.N. Qabar, M.C. Bonner, D.A. Walz, J.S. Wall, S.N. Vinogradov, M.S. Stern, and M. Schmuck, Quaternary Structure of the Giant
Extracellular Haemoglobin of the Leech Macrobdella Decora, J. Mol. Biol. 213 (1990) p. 141.

474. O. H. Kapp, A. N. Qabar and S. N. Vinogradov, Calculation of Subunit Stoichiometry of Large, Multisubunit Proteins from Amino Acid Compositions, Anal. Biochem. 184 (1990) pp. 74-82.

475. Z. Shao and X. D. Wu, Properties of a Four-Electrode Adjustable Electron Mirror as an Aberration Corrector, Rev. Sci. Instrum. 61 (1990) p. 1230.

476. 2. Shao and X. D. Wu, A study on Hyperbolic Mirrors as Correctors, Optik 84 (1990) p. 51.

477. X. D. Wu and Z. Shao, A Qualitative Analysis of Chromatic Aberration of "Thick" Electrostatic Lenses, Optik 84 (1990) p. 66 .

478. S. Ruan and O. H. Kapp, Progress on the SextupoleCorrected Sub-Angstrom Resolution Scanning Transmission Electron Microscope: An Abstract, 1990 Midwest SPIE Meeting (Rosemont, IL, Sept. 27-29, 1990).

479. C. Zmola and O. H. Kapp, Image Processing Utilizing an APL Interface: An Abstract, 1990 Midwest SPIE Meeting 
(Rosemont, IL, Sept. 27-29, 1990).

480. C. Zmola and O. H. Kapp, Networking of an Electron Microscope Laboratory Internally and to the Internet: $\mathrm{An} \mathrm{Ab}$ stract, 1990 Midwest SPIE Meeting (Rosemont, IL, Sept. 27-29, 1990).

481. M. J. Ryan and O. H. Kapp, Development of an Image Processing System on a Second Generation RISC Workstation: An Abstract, 1990 Midwest SPIE Meeting (Rosemont, IL, Sept. 27-29, 1990).

482. O.H. Kapp and S.N. Vinogradov, The Structure of the Hemoglobin of Eudystilia Vancouverii Evidence for Isolated Bracelet Protein, 10th International Biophysics Congress-Satellite Meeting (Whistler, British Columbia, July 1990).

483. S.N. Vinogradov, M. Mainwaring and O.H. Kapp, The Quaternary Structure of the Giant Hemoglobins and Chlorocruorins, 10th International Biophysics CongressSatellite Meeting (Whistler, British Columbia, July 1990).

484. O.H. Kapp M.G. Mainwaring, S.N. Vinogradov and A.V. Crewe, The Extracellular He- moglobin of Amphitrite Ornata: Its Molecular Size, Subunits and Its Dissociation, 10th International Biophysics CongressSatellite Meeting (Whistler, British Columbia, July 1990).

1991

485. A.V. Crewe, An Algebraic approach to the symmetrical einzel lens, Optik 88 (1991) pp. 118-125.

486. A.V. Crewe, A New characterization of the magnetic lens, Optik 89 (1991) pp. 70-74.

487. S. Ruan and O. H. Kapp, Progress on the SextupoleCorrected Sub-Angstrom Resolution Scanning Transmission Electron Microscope, SPIE Proceedings 1396 (1991) pp. 2ก8-310.

488. C. Zmola and O. H. Kapp, Image Processing Utilizing an APL Interface, SPIE Proceedings 1396 (1991) pp. 51.55.

489. C. Zmola and O. H. Kapp, Networking of an Electron Microscope Laboratory Internally and to the Internet, SPIE Proceedings 1396 (1991) pp. 331-334.

490. M. J. Ryan and O. H. Kapp, Development of an Image Processing System on a Second 
Generation RISC Workstation, SPIE Proceedings 1396 (1991) pp. 335-339.

491. D. Walz, J. Chin, R. Timkovich, J. Wall, $O$ Kapp and $S$. Vinogradov, Hierarchy of Globin Complexes: The Quaternary Structure of Eudistylia vancouverii,. J. Mol. Biol. 222 (1991) pp. 1109-1129.

492. Z. Shao, A Note on the Resolution of Low Energy Reflection Electron Microscope Based on Wave Electron Optics, Ultramicroscopy (in press).

493. Z. Shao and Y.L. Wang, On the Optimisation of Ion MicroProbes, J. Vac. Sci. Technol. B. (in press).

494. P.K. Sharma, A.N. Qabar, O.H. Kapp, J.S. Wall and S.N. Vinogradov., The principal subunit of earthworm hernoglo. bin is a dodecamer of heme containing chains, Structure and Function of Invertebrate Oxygen Binding Proteins: Proceedings Biophysical Society Satellite Symposium of the Xth International Biophysics Congress (1991) pp. 65-72. S.N. Vinogradov and O.H. Kapp, eds. Springer-Verlag.

495. P.K. Sharma, A.N. Qabar, O.H. Kapp, J.S. Wall and S.N. Vinogradov., Studies of the Dis. sociation of Eudistylia Vancouverii chlorocruorin,. Structure and Function of Invertebrate Oxygen Binding Proteins: $\quad$ Proceedings Biophysical Society Satellite Symposium of the Xth International Biophysics Congress (1991) pp. 79-86. S.N. Vinogradov and O.H. Kapp, eds. Springer-Verlag.

\section{2}

496. O.H. Kapp and C.-T Chen, Reconstruction from Limited Projection Data, SPIE Proceedings on Biomedical Image Processing and Three-Dimensional Microscopy (1992) pp. 26-29.. Feb. 9-14, San Jose, California.

497. C.-T. Chen, O.H. Kapp and W.H. Wong,. Stochastic Reconstruction of Incomplete Data Sets Using Gibbs Priors in Positron Emission Tomography, SPIE Proceedings on Biomedical Image Processing and Three-Dimensional Microscopy (1992) pp. 131-134.. Feb. 9-14, San Jose, California.

498. O.H. Kapp, Use of an APL Interface on a RISC Workstation, SPIE Proceedings (1992) p. in press., March 19, Chicago Illinois

499. S. Ruan and O.H.Kapp, An Automatic Field Emission Tip 
Conditioning System, Review of Scientific Instruments (1992) p. in press.

500. S. Ruan and O.H.Kapp, Progress on the sextupolecorrected sub-angstrom resolution scanning transmission electron microscope, SPIE Proceedings (1992) $\mathrm{p}$. in press. March 19, Chicago, Illinois (1992).

501. S. Ruan and O.H.Kapp, An Automatic Field Emission Tip Conditioning System for the sub-angstrom field-emission STEM. S. Ruan and O. Kapp SPIE Proceedings (1992) $\mathrm{p}$. in press. March 19, Chicago, Illinois (1992).

502. S. Ruan and O.H.Kapp, Scan System for a Sextupolecorrected Scanning Transmis- sion Electron Microscope, Review of Scientific Instruments (1992) p. in press.

503. S.N. Vinogradov, D.A. Walz, L. Moens, B Polhajdak, O.H. Kapp, Adventitious Variability? The Amino Acid Sequences of Nonvertebrate Globins, (1992) p. submitted.

504. A.V. Crewe, The Three Element Electrostatic Lens, Optik (in press).

505. A.V. Crewe, Electron motion in Tuned Fields. I. The Algebra, Ultramicrscopy (in press).

506. A.V. Crewe, Electron motion in Tuned Fields. II. Some Applications, Ultramicroscopy (in press). 

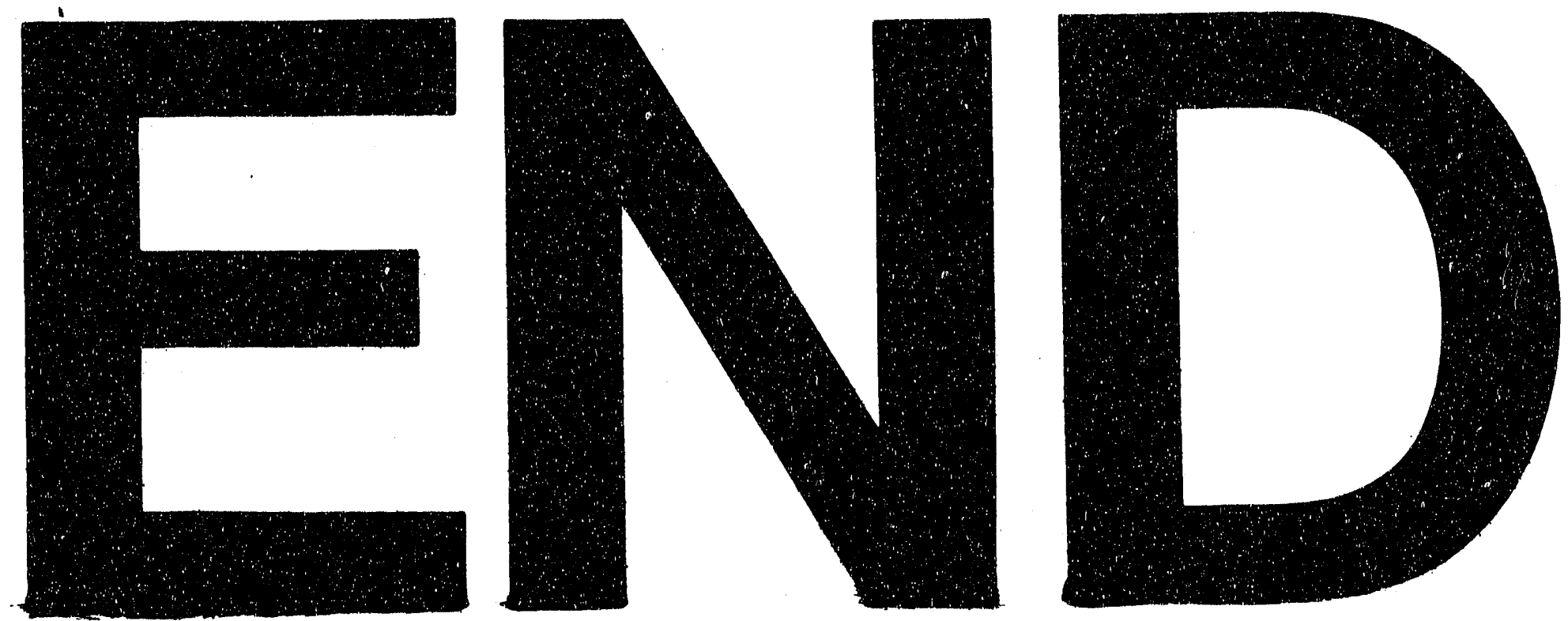

$\because$

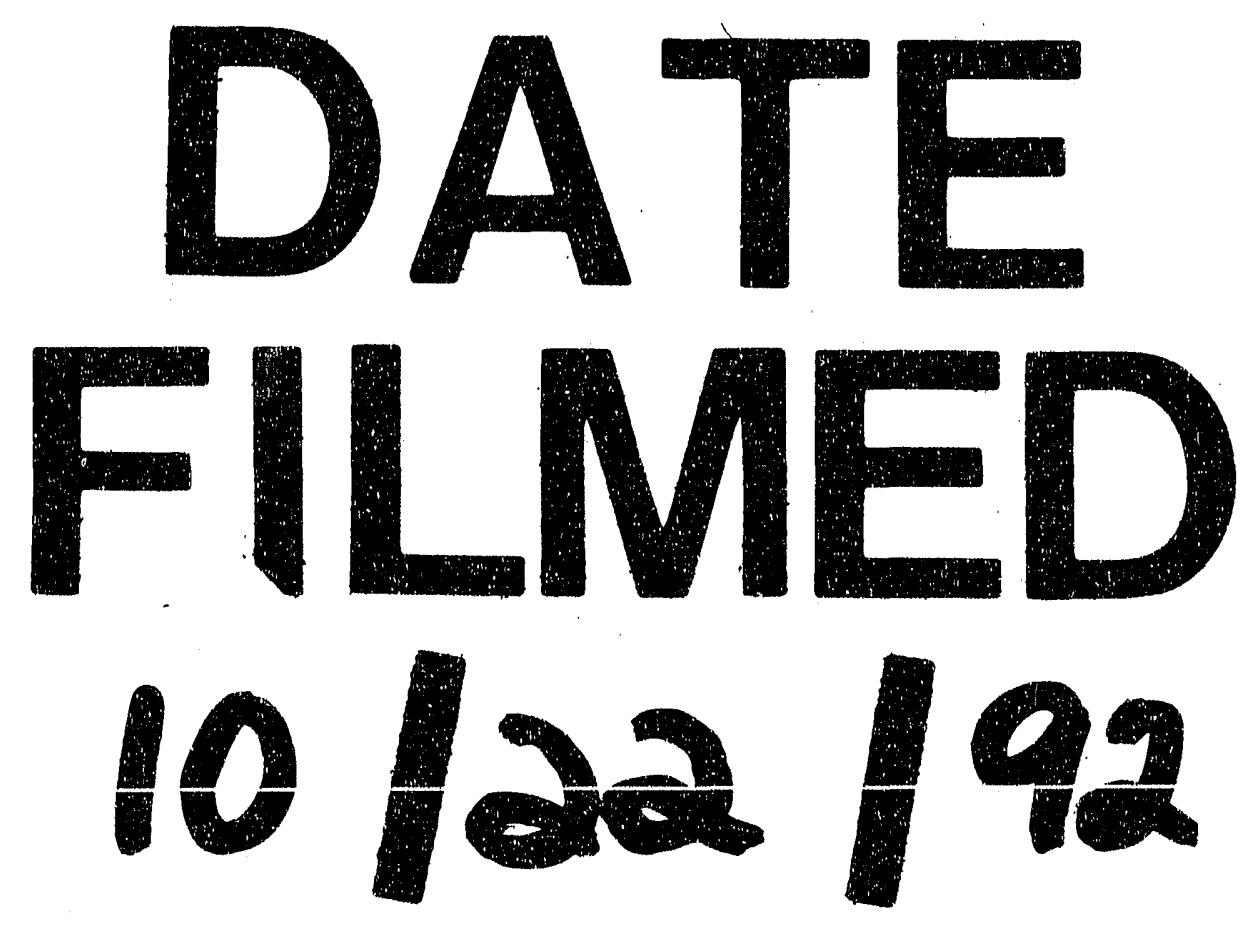


